\title{
HSP70-binding motifs function as protein quality control degrons
}

\author{
Amanda B. Abildgaard ${ }^{1}$, Søren D. Petersen ${ }^{2}$, Fia B. Larsen ${ }^{1}$, Caroline Kampmeyer ${ }^{1}$, \\ Kristoffer E. Johansson ${ }^{1}$, Amelie Stein ${ }^{1}$, Tommer Ravid ${ }^{3}$, Claes Andréasson ${ }^{4}$, Michael K. Jensen ${ }^{2}$, \\ Kresten Lindorff-Larsen ${ }^{1, *}$, Rasmus Hartmann-Petersen ${ }^{1, *}$
}

Running title: Chaperone-linked protein quality control degrons

Keywords: protein unfolding, protein degradation, proteasome, protein stability, protein quality control, chaperone

1: The Linderstrøm-Lang Centre for Protein Science, Department of Biology, University of Copenhagen, Copenhagen, Denmark.

2: Novo Nordisk Foundation Center for Biosustainability, Technical University of Denmark, Kgs. Lyngby, Denmark.

3: Department of Biological Chemistry, The Alexander Silberman Institute of Life Sciences, The Hebrew University of Jerusalem, Jerusalem, Israel.

4: Department of Molecular Biosciences, The Wenner-Gren Institute, Stockholm University, Stockholm, Sweden.

*Corresponding authors: K.L.-L. (lindorff@bio.ku.dk) and R.H.-P. (rhpetersen@bio.ku.dk). 


\begin{abstract}
Protein quality control (PQC) degrons are short protein segments that target misfolded proteins for degradation through the ubiquitin-proteasome system (UPS). To uncover how PQC degrons function, we performed a screen in Saccharomyces cerevisiae by fusing a library of flexible tetrapeptides to the C-terminus of the Ura3-HA-GFP reporter. The identified degrons exhibited high sequence variation but with marked hydrophobicity. Notably, the best scoring degrons constitute predicted Hsp70-binding motifs. When directly tested, a canonical Hsp70 binding motif (RLLL) functioned as a dose-dependent PQC degron that was targeted by Hsp70, Hsp110, Fes1, several Hsp40 J-domain co-chaperones and the PQC E3 ligase Ubr1. Our results suggest that multiple PQC degrons overlap with chaperone-binding sites and that PQC-linked degradation achieves specificity via chaperone binding. Thus, the PQC system has evolved to exploit the intrinsic capacity of chaperones to recognize misfolded proteins, thereby placing them at the nexus of protein folding and degradation.
\end{abstract}




\section{Introduction}

Proteins are diverse and dynamic macromolecules that typically fold into native structures that determine their individual functions. Nevertheless, proteins are at continuous risk of misfolding, which may be accelerated due to mutations, aging or environmental stress conditions. Misfolded proteins are typically prone to form aggregates and often display proteotoxicity via poorly understood mechanisms (Bucciantini et al., 2002). For example, several neurodegenerative disorders have been connected with the accumulation of toxic misfolded protein species (Bates et al., 2015; Poewe et al., 2017). Thus, securing that the proteome is folded and functional is indispensable for cellular fitness. The outcome of protein folding is monitored closely by the cellular protein quality control (PQC) system that relies on both chaperones and the ubiquitin-proteasome system (UPS). Molecular chaperones prevent protein aggregation by promoting de novo folding of newly synthesized proteins, refolding of misfolded proteins, and the assembly of protein complexes (Balchin et al., 2020, 2016; Dahiya and Buchner, 2019). Regulated by Hsp40 J-domain co-chaperones and nucleotide exchange factors (NEF), the heat shock protein 70 (Hsp70) chaperones catalyze protein folding through ATPdependent cycles of substrate binding and release (Kohler and Andréasson, 2020; Rosenzweig et al., 2019). Hsp70 promotes folding by clamping onto hydrophobic stretches flanked by positive charges, and thus binds regions that normally are buried within correctly folded proteins and selectively exposed upon misfolding (Houben et al., 2020; Rousseau et al., 2006; Rüdiger et al., 1997). If folding fails, the persistent misfolded proteins are targeted for degradation through various PQC pathways, including the ubiquitin-proteasome system (UPS). To facilitate degradation by the $26 \mathrm{~S}$ proteasome, proteins are covalently linked to ubiquitin moieties through the sequential actions of E1, E2 and E3 enzymes (Dikic, 2017; Kwon and Ciechanover, 2017; Pohl and Dikic, 2019).

The pathway for PQC degradation of misfolded proteins is not fully resolved, and a key unsettled question is how the specificity is achieved, i.e. how does the PQC system distinguish misfolded 
proteins from the many proteins that should not be degraded. Typically, the UPS obtains specificity through the substrate preference of E3 ubiquitin-protein ligases. Accordingly, a handful of E3s have been connected with PQC-linked degradation of misfolded proteins in the cytosol and nucleus (Hickey et al., 2021; Oh et al., 2018; Samant et al., 2018) but the exact substrate preferences of the PQC E3s are largely unknown. In general, E3s recognize regions in target proteins termed degradation signals or degrons (Varshavsky, 1991). The region interacting with the E3, and thus determining the specificity, is called the primary degron (Guharoy et al., 2016b). However, for degradation, a nearby lysine residue that acts as a ubiquitylation site, the so-called secondary degron, is also required. Finally, a partially unfolded or disordered region in the substrate protein, the tertiary degron, is required for the proteasome to commence unfolding and degradation (Guharoy et al., 2016a).

Besides taking part in PQC, the UPS also performs regulated protein degradation and targets native proteins for degradation, thus managing their cellular turnover. For this purpose, several primary degrons (from here on referred to as degrons) have been characterized. These include the KEN-box (Pfleger and Kirschner, 2000) targeted by the anaphase-promoting complex. Meanwhile, the classical N-end degrons, where specific N-terminal residues elicit degradation (Bachmair et al., 1986; Varshavsky, 2011), as well as the corresponding C-degrons (Koren et al., 2018), serve in both signaling and PQC (Timms and Koren, 2020). However, for misfolded proteins, the so-called PQC degrons remain poorly defined, although a few examples such as Degl and CL1 have been characterized in detail. The Degl degron is situated in the a1-interaction site of the yeast $\alpha 2$ protein, while $C L 1$ is an artificial 16-residue sequence. Both depend on hydrophobic residues mediating the degradation through the Doa10 E3 (Gilon et al., 1998; Johnson et al., 1998; Ravid et al., 2006). As recent data have shown that mutation of degrons play a critical role for oncoprotein stability (Liu et al., 2021; Tokheim et al., 2021), it is essential that we learn more about degron properties. 
It remains unclear how the cell is able to recognize the broad range of different misfolded proteins of the proteome. Growing evidence, however, suggests that the UPS exploits the molecular chaperone system to recognize the highly diverse group of misfolded substrates. For example, both Doa10 and another PQC E3, Ubr1, collaborate with molecular chaperones for degradation via poorly understood mechanisms (Amm et al., 2015; Heck et al., 2010; Kriegenburg et al., 2014; Maurer et al., 2016; Shiber et al., 2013; Singh et al., 2020; Summers et al., 2013). For Ubr1, a direct interaction with Hsp70 has been observed (Summers et al., 2013), indicating that some PQC E3s may delegate substrate recognition to the chaperones. In the same line, the human CHIP E3 directly interacts with Hsp70 and Hsp90 chaperones to ubiquitylate bound protein substrates (Höhfeld and Jentsch, 1997), while the BAG1 and Hsp110 co-chaperones mediate the release of bound substrates at the $26 \mathrm{~S}$ proteasome (Abildgaard et al., 2020; Gersing et al., 2021; Höhfeld and Jentsch, 1997; Kandasamy and Andréasson, 2018; Kriegenburg et al., 2014).

The broad substrate specificity of Hsp70 and its involvement in protein degradation suggest that it plays a fundamental and direct role in targeting misfolded proteins to the UPS via binding their short PQC degrons. By employing an unbiased screen for short degron motifs in the budding yeast Saccharomyces cerevisiae, we find that degron peptides encompass a broad sequence space, but are prevalent in hydrophobic residues and resemble Hsp70-binding motifs. Direct testing of the canonical Hsp70-binding motif RLLL demonstrates an inherent degron capacity, dependent on Hsp70, Hsp110, Hsp40, Ubr1 and the proteasome. Our data indicate that many PQC degrons may simply be regions adept at engaging the Hsp70 substrate-binding cleft. 


\section{Results}

\section{Degron selection reveals high sequence variation with a preference for hydrophobic residues}

To further our understanding of the mechanisms of PQC degradation, we conducted a growth-based screen in yeast using a Ura3-HA-GFP fusion as a reporter (Geffen et al., 2016). In this system, the degron capacity of a C-terminally attached peptide is expressed as a growth phenotype due to the degradation of the Ura3 reporter protein (Fig. 1A). As an example, fusion to the 16-residue CL1 degron sequence (ACKNWFSSLSHFVIHL) (Gilon et al., 1998) promotes proteasomal degradation of the reporter, which results in growth deficiency on uracil-depleted medium (Fig. 1B). The growth defect is due to low cellular abundance of the reporter, as shown by Western blotting (Fig. 1C). Treating cells with the proteasomal inhibitor, bortezomib (BZ), restores protein levels, which in turn rescues the growth defect (Fig. 1BC). Moreover, since the Ura3 enzyme converts 5-fluoroorotic acid (5-FOA) to the toxic 5-fluorouracil compound (Boeke et al., 1984), degradation of the reporter provides cells with resistance to 5-FOA (Fig. 1B) (Gilon et al., 1998). Thus, 5-FOA can be used to select for cells with reporter-degron fusions.

Next, we constructed a library by randomization of four amino acid positions in a short flexible region downstream of the Ura3-HA-GFP reporter. To maximize the diversity of the library, randomization was achieved by insertion of four degenerate codon sets in one of the primers used for PCR prior to assembly by in vivo gap repair (Fig. 1D). Transformed cells were harvested and plated on 5-FOA plates (Fig. 1E). By comparing the number of plated colonies from the treated and untreated libraries, we found that $<0.5 \%$ of the library displayed resistance to 5 -FOA, and can thus be assumed to hold

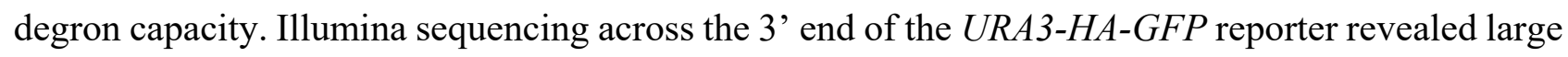
sequence variation among the possible degron motifs (Supplementary File 1), suggesting that either: 1) many specific degron sequences are targeted in parallel by multiple E3s, and/or 2) many different 
degron sequences are targeted by a mechanism of broad specificity. After quality control of our sequencing data, we found ca. 18,000 of the 160,000 possible tetrapeptide sequences in the input library, yet only 883 sequences were recovered after selection on 5-FOA. Analysis of the degron sequences revealed a generally high flexibility within the sequence space of the degron motifs. We found the highest prevalence of hydrophobic residues at positions 1 and 2 as well as positively charged residues at position 1 (Fig. 2A), while polar residues were unfavorable at positions 1 and 2, as were negatively charged residues at positions 3 and 4 . All identified degrons are listed in the supplemental material (Supplementary File 1).

To confirm the screen, the ten most prevalent sequences from the 5-FOA resistant library (Fig. 2B) were independently incorporated into the Ura3-HA-GFP reporter and transformed individually into yeast cells. Their degron capacities were tested by analyzing their resistance to 5-FOA as well as their growth on uracil-depleted medium with and without BZ (Fig. 2C). This confirmed strong degron capacities in eight motifs (RWVW, MMWM, MDLM, GRLW, CYNL, AWHH, PWNM, and MNWL) while two motifs (PQHC and YRAE) did not have significant degron activity. Thus, with this screen, we were able to select sequences, which hold strong degron capacities and find motifs with a high prevalence of hydrophobic residues.

\section{Hsp70/Hsp110-mediated degradation of Hsp70-binding motifs}

Inspired by the enrichment of hydrophobic and basic residues in the 5-FOA resistant library, properties that have been associated with Hsp70 binding (Rüdiger et al., 1997), we used Limbo, a predictor for peptide binding to E. coli Hsp70 (DnaK) (Durme et al., 2009). A high Limbo score indicates greater likelihood for binding, and while we do not find an overall correlation between the sequencing counts and the prediction of the Hsp70 binding, we do find that those sequences most enriched after treatment with 5-FOA are predicted to bind more strongly to Hsp70. For example, 
while the average Limbo score across all 18,706 sequences is $1.79 \pm 0.04$ (mean \pm standard error of the mean), the ten most prevalent sequences from the 5-FOA resistant library have an average Limbo score of $5 \pm 1$ and the average score of the top-100 sequences is $3.0 \pm 0.5$ (Supplementary Fig. S1). Thus, many potent degron sequences are predicted to bind to the substrate-binding site of Hsp70.

Inspired by previous work (Macossay-Castillo et al., 2019), we then asked the question whether there is a correlation between predicted Hsp70 binding and protein abundance more generally. We thus calculate Limbo scores for the yeast proteome and consider only those residues predicted to be disordered, and thus solvent accessible. We find that the mean number of Hsp70 binding sites among these residues differs for different levels of abundance and half-life, indicating that exposed Hsp70 binding sites might influence protein abundance and half-life in general (Supplementary Fig. S2).

The $S$. cerevisiae genome encodes multiple cytosolic Hsp70 paralogs. For degradation, these converge at Hsp110 (Andréasson et al., 2008), a Hsp70 NEF, which mediates substrate release and degradation at the 26S proteasome (Kandasamy and Andréasson, 2018). To test whether the degron motifs from our screen undergo Hsp70/Hsp110-mediated degradation, we analyzed protein levels of the ten most prevalent degron sequence motifs in the sse1-200 sse $2 \Delta$ temperature-sensitive Hsp110 double-mutant strain (Fig. 2D) (Kaimal et al., 2017). The cellular abundance of the eight degron motifs (RWVW, MMWM, MDLM, GRLW, CYNL, AWHH, PWNM, MNWL) were increased at the restrictive temperature $\left(30^{\circ} \mathrm{C}\right)$ compared to the permissive temperature $\left(25^{\circ} \mathrm{C}\right)$, showing that Hsp110 is required for the degradation of these degrons.

\section{The consensus Hsp70-binding motif (RLLL) functions as a degron}

Having established that the screen largely selects for hydrophobic chaperone-dependent degrons, we next decided to approach the issue of PQC specificity in reverse by directly testing the degron capacity of a known Hsp70-binding motif. The so-called APPY peptide, which we term here as 1xRLLL, is a 
canonical Hsp70-binding, 21-mer peptide (CALLQSRLLLSAPRAAATARY), originally identified in the precursor of chicken mitochondrial aspartate aminotransferase (Montgomery et al., 1999; Schmid et al., 1994, 1992). The central RLLL motif is critical for binding Hsp70, and the structure of Hsp70 bound to an RLLL peptide (Zhu et al., 1996) shows the RLLL sequence placed within the Hsp70 substrate binding groove (Fig. 3A).

We prepared a set of reporter-peptide fusions to test the degron capacity of the RLLL motif (Fig. 3B). To potentially increase avidity, we introduced the APPY peptide in one (1xRLLL), two (2xRLLL) or three (3xRLLL) copies in the C-terminus of the Ura3-HA-GFP reporter. We also constructed variants, RAAA and DAAA, which we predicted to portray intermediate or poor degron capacities, respectively (Rüdiger et al., 1997). The reporter-constructs were expressed in yeast cells, and protein levels were analyzed by microscopy (Fig. 3C) and Western blotting (Fig. 3D). The RLLL-fused reporter was expressed at low levels, which decreased further with increasing repeats of the peptide (2xRLLL and 3xRLLL). In contrast, for the RAAA and DAAA variants, the levels were, respectively, partly or completely restored, thus reflecting their predicted Hsp70 affinities from in vitro studies (Rüdiger et al., 1997). This indicates that RLLL-linked degradation of the reporter correlates with the Hsp70-binding ability. Treating cells with the translational inhibitor, cycloheximide (CHX), caused the RLLL-level to decrease further, while inhibition of the proteasome caused an increase (Fig. 3E), proving that the reduced protein level is caused by proteasomal degradation. Meanwhile, DAAAlevels remained unchanged by both treatments. Accordingly, when we assessed the growth phenotypes of the reporter-constructs on uracil-depleted medium, we observed that proteasome inhibition rescued the growth of cells with degron-fused reporters (Fig. 3F). Collectively, these results show that decreased cellular abundances are due to proteasomal degradation of the RLLL-linked reporters. Although the RLLL motif was present in the input screening library, it did not appear as 5FOA resistant in the screen. Since we, however, here established its degron capacity, we suspected 
that RLLL might be a weaker degron than those identified in the screen. To test this, we performed plating assays with cells expressing the Ura3-HA-GFP reporter fused to RLLL and two of the best scoring hits, RWVW and MMWM, on media with 5-FOA. Relative to the RWVW degron, colony formation was $98.4 \pm 2.5 \%$ (mean \pm standard error of the mean) for MMWM, while for RLLL this dropped to only $46.5 \pm 9.6 \%$, thus indicating that that RLLL is indeed a weaker degron compared to the RWVW and MMWM motifs, which may explain why it was not found in the screen.

Previous studies have shown a positive correlation between protein insolubility and degradation of PQC targets (Abildgaard et al., 2019; Fredrickson et al., 2013; Gallagher et al., 2014; Jones et al., 2020; Summers et al., 2013). To test this for the RLLL peptides, we separated whole cell lysates into soluble and insoluble fractions by centrifugation. This revealed that the RLLL motif induces insolubility of the reporter construct (Supplementary Fig. S3A). While the solubility of the reporter decreased with the number of RLLL motifs in the construct, mutations within the RLLL motif reduced (RAAA) or eliminated (DAAA) this effect (Supplementary Fig. S3A). Thus, the degronactivity correlates with protein insolubility.

Finally, we tested the role of residues flanking the RLLL sequence by mutagenesis. Both growth assays (Supplementary Fig. S3B) and protein abundances (Supplementary Fig. S3C) of mutant reporter-constructs showed that, the introduction of negative charges near the RLLL sequence disrupts its degron capacity. This confirmed that the degron capacity depends on the RLLL motif, and indicates that it relies on binding to Hsp70, which is known to be highly sensitive to the presence of negative charges flanking the binding site (Rousseau et al., 2006). As a further control to support that the RLLL fragment is likely exposed, a circular dichroism (CD) analysis of the peptide variants confirmed that the peptides hold no regular secondary structure (Supplementary Fig. S3D).

The RLLL-degron relies on chaperones, co-chaperones and the E3 Ubr1 
To further explore the degradation of the RLLL-degron, we analyzed the cellular abundance of the reporter upon mutation of various chaperones, co-chaperones and UPS components. First, we used a high copy expression vector for the GFP-1xRLLL fusion in immunoprecipitation assays with the yeast Hsp70 homologue Ssa1. To limit the degradation of the degron fusions, BZ was added to the cultures 4 hours prior to lysis. As anticipated, the GFP-1xRLLL fusion protein interacted with Ssa1, while control GFP did not (Fig. 4A). This interaction was lost by replacing the RLLL motif with either RAAA or DAAA. Moreover, similar to RLLL, the RWVW and MMWM motifs interact with Ssal (Fig 4A). When Hsp70 was inhibited with myricetin (Chang et al., 2011) the level of the Ura3HA-GFP-1xRLLL reporter increased (Fig. 4B). Also, as expected, and similar to the degrons identified from our screen (Fig. 2C), degradation of the RLLL degron was dependent on the yeast Hsp1 10 homologues Sse1 and Sse2 (Fig. 4C). Similar stabilization was observed in a strain lacking the well-characterized Hsp70 NEF, Fes1 (Fig. 4D), which has an established role in UPS-mediated degradation (Gowda et al., 2018, 2013). We also analyzed strains deleted for various Hsp40 J-domain co-chaperones (Fig. 4D). We found that deletion of the J-domain proteins Jjj3, Apj1, Zuo1 and Caj1 increased cellular abundance of the RLLL-fused reporter (Fig. 4D), suggesting that they are involved in the degradation of RLLL. Similarly, we tested selected PQC E3 ubiquitin-protein ligases and observed a strong effect in the $u b r l \Delta$ strain (Fig. 4E), indicating that Ubr1 plays a critical role in degradation of the RLLL reporter, which is in line with its previously published role in PQC (Summers et al., 2013). Accordingly, and as reported by others before (Summers et al., 2013), we observed an interaction between Ubr1 and Ssa1 in vivo (Supplementary Fig. S4). Growth analysis showed reduced growth on uracil-depleted medium in strains with low abundance of the RLLL-fused reporter (Fig. 4FG). Intriguingly, in strains lacking the yeast-specific Hsp104 (Fig. 4D) and Jjj2 (Fig. 4DF), a reduced growth on uracil-depleted medium and decreased steady-state levels were observed. 
This suggests that these components block RLLL-degradation, perhaps by affecting the aggregation or solubility of the RLLL reporter.

In conclusion, the proteasomal degradation route for proteins carrying RLLL degrons requires the activity of Hsp70, Hsp110 and Fes1, several JDPs, as well as the E3 ubiquitin-protein ligase Ubr1 (Fig. 4H). 


\section{Discussion}

In this study, we demonstrate that substrate binding to Hsp70 is correlated with UPS-mediated degradation. Accordingly, Hsp70 must play an essential role in both protein (re)folding and protein degradation. In our experimental system, the chaperone-binding motif is artificially grafted onto the Ura3-HA-GFP reporter, and since the chaperones cannot refold and bury these fragments, this effectively uncouples degradation from folding, thus allowing us to separately study the role of Hsp70 in degradation. Albeit this model differs from PQC degron-exposure in a natural full-length misfolded protein, which indisputably is more complex (Kampmeyer et al., 2021), our findings lead us to suggest a model (Fig. 4H). First, exposure of a chaperone-binding motif, induced by misfolding, will lead to initial chaperone engagement. In a second step, PQC E3s will be recruited to the chaperonesubstrate complex and target the misfolded protein for proteolysis through ubiquitylation. Thus, if the substrate (re)folds after chaperone engagement, the chaperone-binding motif will become buried and will no longer target the protein for proteolysis. Proteins that persistently occupy misfolded conformations will, however, remain associated with Hsp70 and eventually be targeted for degradation.

As we find the outcome of any substrate-chaperone interaction to ultimately depend on the presence of certain PQC proteins, our results indicate that any substrate that Hsp70 binds will risk degradation. This provides a new perspective on how Hsp70 chaperones perform triage of bound substrates, by suggesting that the degradation system largely or fully relegates substrate recognition to the chaperones. A prediction from this model is that the refolding rates of substrates are more rapid than association with components required for PQC-linked degradation. According to the Saccharomyces Genome Database, the combined abundance of Ssa1 and Ssa2 is $~ 500,000$ molecules/cell, while the PQC E3s are all present at levels roughly two orders of magnitude lower. Hence, a simple stochastic model where PQC E3s randomly ubiquitylate chaperone clients may result in specific clearance of 
irreversibly misfolded proteins from the cell. An additional level of specificity and regulation can then be achieved through repeated cycles of binding and release by the chaperone, which involve recruitment of specific co-chaperones, including J-domain proteins, NEFs like Hsp110 or BAGdomain proteins and E3s. Other UPS components such as deubiquitylating enzymes and PTMs of chaperones are also likely to play a role. In stress situations, the balance of these components is perturbed, which in turn affects the specificity of the PQC system and thus regulates the balance between folding and degradation. Accordingly, a system-wide understanding of the intricate proteostasis systems is necessary in order to predict the fate of any given misfolded protein (Powers and Gierasch, 2021).

An obvious advantage of Hsp70 and other chaperones playing a central role in PQC degradation is that PQC E3s in this way exploit a pre-existing cellular system capable of recognizing non-native proteins. From an evolutionary perspective, this seems intuitive, since the chaperone system arose early to regulate protein folding, whereas the UPS machinery is comparably new (Rebeaud et al., 2021).

A number of studies have aimed at clarifying the sequence features that constitute good Hsp70binding elements (Clerico et al., 2021; Durme et al., 2009; McCarty et al., 1995; Nordquist et al., 2021; Rüdiger et al., 1997; Zhu et al., 1996). We find that degron sequences hold similar features, and unsurprisingly, that residues flanking the degron motif also critically affect the degron activity. The sequence context likely determines the exposure of the degron but may also more directly affect degron recognition by chaperones. For instance, it has been shown that hydrophobic regions flanked by negative charges rarely engage with chaperones (Houben et al., 2020; Koopman and Rüdiger, 2020; Rousseau et al., 2006), which is supported by our observations.

Previous degron studies have also found high sequence variability and dependence on chaperones (Geffen et al., 2016; Maurer et al., 2016). Presumably, degron motifs must have a high sequence 
variability since the UPS must potentially be able to degrade the entire proteome. The genome thus encodes many different E3 ligases, each with different substrate preferences. However, since we find that PQC degron sequences often overlap with Hsp70-binding motifs, the high sequence variability within degron motifs may also reflect the promiscuity of substrate binding to Hsp70 (Clerico et al., 2021; Rüdiger et al., 1997; Zhuravleva and Gierasch, 2015). Hence, unlike classical regulatory degrons such as the KEN-box, PQC degrons seem not to adhere to simple consensus motifs but rather to rely on the overall physical properties of the degron, such as hydrophobicity and charge patterns. This was shown for substrates of the yeast E3, San1, that targets misfolded nuclear proteins for degradation through direct interactions with exposed hydrophobic regions in the target protein (Gardner et al., 2005). Yet, even in the case of San1, chaperones can play a role both up- and downstream of the San1-catalyzed ubiquitylation (Guerriero et al., 2013; Jones et al., 2020; Kriegenburg et al., 2014).

In conclusion, the collective PQC degron catalogue may simply be sequence motifs that are recognized by PQC proteins including the abundant Hsp70. Thus, much like the way the immune system only detects intruding antigens and not self-like motifs, the PQC detection system has evolved to recognize sequences that under normal conditions are not present (buried in native proteins). During stress, stable protein structures are destabilized and expose these sequences that take the role as degrons. Thus, a PQC degron can be any sequence or structure that is not normally found on a protein surface. Accordingly, the presence of degron motifs in less structured proteins, like the intrinsically disordered proteins (IDPs), would necessarily be selected against, or in the case they are not, the degron would require activation, e.g. by phosphorylation or the protein would be expected to be highly unstable, which is what current studies indeed reflect (Guharoy et al., 2016b). 


\section{Materials and methods}

\section{Yeast strains and plasmids}

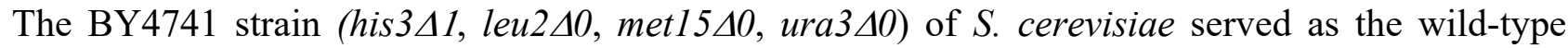
control. Deletion strains were obtained from the Euroscarf collection. The sse 1-200sse $2 \Delta$ temperature sensitive strain has been described before (Kaimal et al., 2017). Cells were grown in YPD (2\% glucose, $2 \%$ peptone, $1 \%$ yeast extract) or synthetic complete (SC) media ( $2 \%$ glucose, $0.67 \%$ yeast nitrogen base without amino acids, $0.2 \%$ drop out supplement) at $30^{\circ} \mathrm{C}$, unless otherwise stated. For high-level expression we used the pESC plasmid (Genscript) and glucose was substituted for galactose. The Ubr1-HA expression plasmid has been described before (Gowda et al., 2013). The pTR1412 plasmid for expressing the Ura3-HA-GFP fusion has been described before (Geffen et al., 2016). Transformation with DNA was performed as described previously (Gietz and Schiestl, 2007).

\section{Library construction and selection}

Plasmids and polymerase chain reaction (PCR) products were purified using kits from MachereyNagel. PCR fragments were amplified using Q5 High-Fidelity 2x Master Mix (New England Biolabs). The primers (IDT) are listed in the Supplementary Table S1. The degron library was constructed using gap repair (Eckert-Boulet et al., 2012). The gap repair was performed with three PCR fragments amplified from and covering the entire pTR1412-1xRLLL plasmid, one of which contained a degron tag with 4 randomized codons across the RLLL motif (Trimer 20 codon mixes from IDT). Briefly, 0.1 pmol of fragment 1 (part of the LEU2 marker, URA3 and GFP; $4149 \mathrm{bp}$ ), 2 pmol of fragment 2 (degron tag $162 \mathrm{bp}$ ), and 0.1 pmol fragment 3 (missing part of the LEU2 marker in fragment $1 ; 3828 \mathrm{bp}$ ) were transformed into BY4741 cells. Transformed colonies were scraped and pooled from 11 individual transformation plates. The estimated total number of colonies pooled was 
bioRxiv preprint doi: https://doi.org/10.1101/2021.12.22.473789; this version posted December $22,2021$. The copyright holder for this preprint (which was not certified by peer review) is the author/funder, who has granted bioRxiv a license to display the preprint in perpetuity. It is made available under aCC-BY-NC-ND 4.0 International license.

120,000-130,000. $2 \mathrm{~mL}$ YPD was inoculated with the pooled library to reach $\mathrm{OD}_{600 \mathrm{~nm}}=0.3$ and left to grow overnight at $30^{\circ} \mathrm{C}$. A 1:10 dilution of the culture was plated onto $0.8 \mathrm{mg} / \mathrm{mL} 5$-FOA selection plates without leucine. Colonies resistant to 5-FOA were scraped off and pooled, and were estimated to represent $<0.5 \%$ of the untreated library. ImageJ (version 1.51) was used for colony counting and set to include colonies between $10-1000 \mu \mathrm{m}$ in size.

\section{Sequencing and statistical analyses}

DNA was extracted from overnight cultures using Yeast DNA Extraction Kit (ThermoFisher). This served as template in a PCR reaction amplifying $224 \mathrm{bp}$ containing the randomized degron tag codons within $50 \mathrm{bp}$ from one end. Purified PCR products from different samples were indexed using Nextera XT indexing. The indexed amplicons were quantified using Qubit 2.0 Fluorimeter (Life Technologies), pooled in a molar ratio of 1:3 for untreated (sample 1) and 5-FOA treated (sample 2) samples, respectively, and sequenced on Illumina MiSeq using 75-bp reads. The randomized degron tag codons were extracted from the sequencing reads using the cutadapt command-line tool (Martin, 2011) to remove flanking regions. All processed reads that did not have flanking regions removed or that after removal did not span exactly 12 nucleotides were discarded. Furthermore, we determined the number of reads needed for a trusted sequence to be 50 and 300 reads for samples 1 and 2, respectively by only allowing $\sim 1 \%$ sequence codons to be outside the set of 20 codons present in the Trimer 20 mix. In total, 18,000 and 883 different degron tag sequences, passed this cutoff from samples 1 and 2, respectively. Raw sequencing reads are available at doi: 10.17894/ucph.0f42dd43a46c-4164-a80f-a7d3dd8f4a4d.

\section{Yeast growth assays}


Cells in exponential growth phase were washed in sterile water and adjusted to $\mathrm{OD}_{600 \mathrm{~nm}}=0.4$. A 1:5 serial dilution was spotted in $5 \mu \mathrm{L}$ droplets on plates containing appropriate selection media and relevant chemical compounds: $1 \mathrm{mM}$ bortezomib (LC laboratories), $0.8 \mathrm{mg} / \mathrm{mL}$ 5-FOA (Sigma). Plates were incubated at $30^{\circ} \mathrm{C}$, and growth phenotypes were analyzed after $48-72$ hours.

\section{Microscopy}

Expression was induced with $0.1 \mathrm{mM} \mathrm{CuSO}_{4}$ for 18 hours at $30{ }^{\circ} \mathrm{C}$. Images were recorded using a Carl Zeiss Axio Vert.A1 microscope equipped with a 63x objective and a digital camera (Carl Zeiss AxioCam ICm1).

\section{SDS-PAGE and Western blotting}

Protein levels in whole-cell lysates were analyzed by SDS-PAGE and Western blotting. Cycloheximide (Sigma) was used at a final concentration of $100 \mu \mathrm{g} / \mathrm{mL}$. Bortezomib (LC Laboratories) was used at a final concentration of $1 \mathrm{mM}$. Myricetin (Sigma) was used at a final concentration of $100 \mu \mathrm{M}$. An equal number of cells $\left(1-2 \times 10^{8}\right.$ cells $)$ was harvested and lysed using glass beads and a FastPrep Bead Beating System (MP Biomedicals). For denaturing cell lysis, cells were lysed in 20\% TCA (Sigma) and proteins were extracted by centrifugation and washed in $80 \%$ acetone. Finally, proteins were resuspended and boiled in 4x SDS sample buffer $(250 \mathrm{mM}$ Tris/HCl pH 6.8, $8 \%$ SDS, 40\% glycerol, $0.05 \%$ bromophenol blue, $0.05 \%$ pyronin $\mathrm{G}, 2 \% \beta$-mercaptoethanol). For analysis of protein solubility, proteins were lysed in $25 \mathrm{mM}$ Tris/ $\mathrm{HCl} \mathrm{pH} 7.4,50 \mathrm{mM} \mathrm{NaCl}, 10 \%$ glycerol and $2 \mathrm{mM} \mathrm{MgCl} 2$ and split into fractions by centrifugation (13,000 g, $30 \mathrm{~min})$. Then, the volume of the pellet fractions was adjusted to match the volume of the supernatants prior to the addition of SDS sample buffer. The samples were separated by SDS-PAGE on $12.5 \%$ acrylamide gels and transferred to nitrocellulose membranes (Advantec). The membranes were blocked in 5\% 
bioRxiv preprint doi: https://doi.org/10.1101/2021.12.22.473789; this version posted December $22,2021$. The copyright holder for this preprint (which was not certified by peer review) is the author/funder, who has granted bioRxiv a license to display the preprint in perpetuity. It is made available under aCC-BY-NC-ND 4.0 International license.

fat-free milk powder, $5 \mathrm{mM} \mathrm{NaN}_{3}$ in $\mathrm{PBS}\left(4.3 \mathrm{mM} \mathrm{Na}_{2} \mathrm{HPO}_{4}, 1.47 \mathrm{mM} \mathrm{KH}_{2} \mathrm{PO}_{4}, 137 \mathrm{mM} \mathrm{NaCl}, 2.7\right.$ $\mathrm{mM} \mathrm{KCl,} \mathrm{pH}$ 7.4). The primary antibodies and their sources were: anti- $\alpha$-tubulin (Abcam, YL1/2 MA1-80017), anti-Pmal (Abcam, 40B7 Ab4645), anti-GFP (Chromotek, 3H9 3h9-100), anti-Myc (Chromotek, 9E1 9e1-100), anti-HA (Roche, 15645900), anti-Pgk1 (Invitrogen, 22C5D8). Appropriate species-specific secondary antibodies conjugated to horseradish peroxidase were from DAKO.

\section{Co-immunoprecipitation}

Cultures were incubated overnight in SC medium with $2 \%$ galactose instead of glucose to induce high-level expression from the pESC plasmid. Bortezomib (LC Laboratories) was added to a final concentration of $1 \mathrm{mM} 4$ hours prior to harvest. $1-2 \times 10^{8}$ cells were lysed by mechanical lysis with glass beads in native lysis buffer $(150 \mathrm{mM}$ Tris/ $\mathrm{HCl} \mathrm{pH} \mathrm{7.5,} 50 \mathrm{mM} \mathrm{NaCl}, 1 \mathrm{mM}$ PMSF and Complete protease inhibitors (Roche)). Cell debris was cleared from lysates by centrifugation (13,000 g, 30 min). The supernatants were incubated with GFP-trap resin (Chromotek) overnight at $4{ }^{\circ} \mathrm{C}$. After extensive washing in lysis buffer, proteins were eluted with SDS sample buffer and analyzed by SDSPAGE and Western blotting.

For the co-precipitation of Ubr1-HA with Ssa1-myc, we followed the above procedure but used a native lysis buffer containing $150 \mathrm{mM} \mathrm{NaCl}, 50 \mathrm{mM}$ Hepes pH 7.4, $1 \mathrm{mM}$ EDTA, 0.1\% Triton X100, $1 \mathrm{mM}$ PMSF and Complete protease inhibitors (Roche), precleared cell extracts (10,000, $5 \mathrm{~min})$ and incubated the supernatants with Myc-trap resin (Chromotek) for 3 hours at $4{ }^{\circ} \mathrm{C}$.

\section{Circular dichroism}

Amidated and acetylated peptides were synthesized by TAG Copenhagen A/S (Copenhagen, Denmark) with the following sequences: APPY-RLLL (CALLQSRLLLSAPRRAAATARY), 
(CAAAQSRLLLSAPDDAAATARY), APPY-var7 (ATQLCSRLLLAYRRPAASALAR) and APPY-rev (YRATAAARRPASLLLRSQLLAC). Approximately $0.5 \mathrm{mg}$ of each lyophilized peptide was weighed out and dissolved in $0.5 \mathrm{~mL} 10 \mathrm{mM}$ sodium phosphate $\mathrm{pH}$ 7.0. After centrifugation at $15,000 \mathrm{~g}, 4^{\circ} \mathrm{C}$ for $20 \mathrm{~min}$, the supernatant was transferred to a new tube, and the peptide concentration was estimated from the absorbance at $280 \mathrm{~nm}$ and $214 \mathrm{~nm}$ (Kuipers and Gruppen, 2007). The peptides were diluted to $0.075 \mathrm{mg} / \mathrm{mL}(\sim 30 \mu \mathrm{M})$ with $10 \mathrm{mM}$ sodium phosphate $\mathrm{pH} 7.0$, TCEP was added to a final concentration of $0.6 \mathrm{mM}$, and the $\mathrm{pH}$ was corrected to 7.0. A Jasco J-815 CD spectropolarimeter was used for recording Far-UV CD spectra from $260 \mathrm{~nm}$ to $190 \mathrm{~nm}$ at $20{ }^{\circ} \mathrm{C}$ with $1 \mathrm{~nm}$ bandwidth, $0.1 \mathrm{~nm}$ data pitch, 2 second D.I.T. and $10 \mathrm{~nm} / \mathrm{min}$. A total of 10 scans were accumulated and averaged. Similar spectra of the buffer alone were recorded with identical settings and subtracted.

\section{Limbo calculations}

We used a local installation of the Limbo software (Durme et al., 2009) to predict Hsp70 binding for all peptides in the Ura3-HA-GFP-reporter library, and extracted the strongest binding site predicted within each sequence. For calculations on the yeast proteome, we calculated un-weighted Limbo scores of 7-residue fragments and assigned the central residue position using Limbo (Durme et al., 2009). The maximum score across 15 residues was following assigned the central residue to obtain a score for a stretch totaling 21 residues, the length of the APPY peptide. We used yeast proteome abundance data collected by Dubreuil et al. (Dubreuil et al., 2019), and complemented these with half-life data for 1993 of the 4533 proteins (Christiano et al., 2014). As for abundance, proteins were assigned to one of 10 bins based on half-life with the same number of proteins in each bin. Proteins with any membrane-associated residues were excluded from this analysis to avoid that the generally 
hydrophobic patches give false positives. Limbo scores were assigned each residue and the $30 \%$ highest scoring residues were considered Hsp70 binding sites. As a proxy for solvent exposure, the $30 \%$ of residues with highest disorder (IUpred) score (Mészáros et al., 2018), as assigned by Dubreuil et al., were considered disordered. The data is available at https://github.com/KULLCentre/papers/tree/main/2021/Hsp70-Abildgaard-et-al. 


\section{Acknowledgements}

The authors thank Anne-Marie Lauridsen and Søren Lindemose for excellent technical assistance, Peter S. Millard for help with the circular dichroism, Asta B. Andersen for helping with the illustrations, and Frederikke V. Larsen for assistance early in the project. We thank Profs. F. Rousseau and J. Schymkowitz (VIB) for sharing the Limbo Software.

\section{Conflicts of interest}

No conflicting interests to declare.

\section{Funding}

This work was supported by the Novo Nordisk Foundation (https:// novonordiskfonden.dk) challenge programme PRISM (NNF18OC0033950; to A.S, K.L.L. \& R.H.P.), REPIN (NNF18OC0033926; to R.H.P.) and NNF18OC0052441 and NNF0071057 (to R.H.P.), the Lundbeck Foundation (https://www.lundbeckfonden.com) R249-2017-510 (to R.H.P.) and R272-2017-4528 (to A.S.), the Danish Council for Independent Research (Natur og Univers, Det Frie Forskningsråd) (https://dff.dk/) 7014-00039B (to R.H.P.), the Villum Foundation (https://veluxfoundations.dk/) 40526 (to R.H.P.), and the European Commission Horizon 2020 programme (MIAMi: No. 722287) (to M.K.J.). The funders had no role in study design, data collection and analysis, decision to publish, or preparation of the manuscript.

\section{Author contributions}

A.B.A., S.D.P., F.B.L., C.K. and K.E.J. conducted the experiments. Data analyses by A.B.A., S.D.P, K.E.J., A.S., T.R., C.A., M.K.J., K.L.L., and R.H.P. Experimental design by A.B.A., S.D.P., M.K.J., 
bioRxiv preprint doi: https://doi.org/10.1101/2021.12.22.473789; this version posted December $22,2021$. The copyright holder for this

preprint (which was not certified by peer review) is the author/funder, who has granted bioRxiv a license to display the preprint in perpetuity. It is made available under aCC-BY-NC-ND 4.0 International license.

T.R., and R.H.P. A.B.A., C.A., K.L.L., and R.H.P. conceived the study. A.B.A. and R.H.P. wrote the paper. 


\section{References}

Abildgaard, A.B., Gersing, S.K., Larsen-Ledet, S., Nielsen, S.V., Stein, A., Lindorff-Larsen, K., Hartmann-Petersen, R., 2020. Co-Chaperones in Targeting and Delivery of Misfolded Proteins to the 26S Proteasome. Biomolecules 10. https://doi.org/10.3390/biom10081141

Abildgaard, A.B., Stein, A., Nielsen, S.V., Schultz-Knudsen, K., Papaleo, E., Shrikhande, A., Hoffmann, E.R., Bernstein, I., Gerdes, A.-M., Takahashi, M., Ishioka, C., Lindorff-Larsen, K., Hartmann-Petersen, R., 2019. Computational and cellular studies reveal structural destabilization and degradation of MLH1 variants in Lynch syndrome. eLife 8, e49138. https://doi.org/10.7554/eLife.49138

Amm, I., Norell, D., Wolf, D.H., 2015. Absence of the Yeast Hsp31 Chaperones of the DJ-1 Superfamily Perturbs Cytoplasmic Protein Quality Control in Late Growth Phase. PLoS One 10, e0140363. https://doi.org/10.1371/journal.pone.0140363

Andréasson, C., Fiaux, J., Rampelt, H., Mayer, M.P., Bukau, B., 2008. Hsp110 Is a Nucleotideactivated Exchange Factor for Hsp70. J. Biol. Chem. 283, 8877-8884. https://doi.org/10.1074/jbc.M710063200

Bachmair, A., Finley, D., Varshavsky, A., 1986. In vivo half-life of a protein is a function of its amino-terminal residue. Science 234, 179-186. https://doi.org/10.1126/science.3018930

Balchin, D., Hayer-Hartl, M., Hartl, F.U., 2020. Recent advances in understanding catalysis of protein folding by molecular chaperones. FEBS Letters 594, 2770-2781. https://doi.org/10.1002/1873-3468.13844

Balchin, D., Hayer-Hartl, M., Hartl, F.U., 2016. In vivo aspects of protein folding and quality control. Science 353. https://doi.org/10.1126/science.aac4354

Bates, G.P., Dorsey, R., Gusella, J.F., Hayden, M.R., Kay, C., Leavitt, B.R., Nance, M., Ross, C.A., Scahill, R.I., Wetzel, R., Wild, E.J., Tabrizi, S.J., 2015. Huntington disease. Nat Rev Dis Primers 1, 15005. https://doi.org/10.1038/nrdp.2015.5

Boeke, J.D., LaCroute, F., Fink, G.R., 1984. A positive selection for mutants lacking orotidine-5'phosphate decarboxylase activity in yeast: 5-fluoro-orotic acid resistance. Mol Gen Genet 197, 345-346. https://doi.org/10.1007/BF00330984

Bucciantini, M., Giannoni, E., Chiti, F., Baroni, F., Formigli, L., Zurdo, J., Taddei, N., Ramponi, G., Dobson, C.M., Stefani, M., 2002. Inherent toxicity of aggregates implies a common mechanism for protein misfolding diseases. Nature 416, 507-511. https://doi.org/10.1038/416507a

Chang, L., Miyata, Y., Ung, P.M.U., Bertelsen, E.B., McQuade, T.J., Carlson, H.A., Zuiderweg, E.R.P., Gestwicki, J.E., 2011. Chemical Screens against a Reconstituted Multiprotein Complex: Myricetin Blocks DnaJ Regulation of DnaK through an Allosteric Mechanism. Chemistry \& Biology 18, 210-221. https://doi.org/10.1016/j.chembiol.2010.12.010

Christiano, R., Nagaraj, N., Fröhlich, F., Walther, T.C., 2014. Global Proteome Turnover Analyses of the Yeasts S. cerevisiae and S. pombe. Cell Reports 9, 1959-1965. https://doi.org/10.1016/j.celrep.2014.10.065

Clerico, E.M., Pozhidaeva, A.K., Jansen, R.M., Özden, C., Tilitsky, J.M., Gierasch, L.M., 2021. Selective promiscuity in the binding of E. coli Hsp70 to an unfolded protein. PNAS 118. https://doi.org/10.1073/pnas.2016962118

Dahiya, V., Buchner, J., 2019. Functional principles and regulation of molecular chaperones. Adv Protein Chem Struct Biol 114, 1-60. https://doi.org/10.1016/bs.apcsb.2018.10.001

Dikic, I., 2017. Proteasomal and Autophagic Degradation Systems. Annu. Rev. Biochem. 86, 193224. https://doi.org/10.1146/annurev-biochem-061516-044908 
Dubreuil, B., Matalon, O., Levy, E.D., 2019. Protein Abundance Biases the Amino Acid Composition of Disordered Regions to Minimize Non-functional Interactions. Journal of Molecular Biology 431, 4978-4992. https://doi.org/10.1016/j.jmb.2019.08.008

Durme, J.V., Maurer-Stroh, S., Gallardo, R., Wilkinson, H., Rousseau, F., Schymkowitz, J., 2009. Accurate Prediction of DnaK-Peptide Binding via Homology Modelling and Experimental Data. PLOS Computational Biology 1000475. https://doi.org/10.1371/journal.pcbi.1000475

Eckert-Boulet, N., Pedersen, M.L., Krogh, B.O., Lisby, M., 2012. Optimization of ordered plasmid assembly by gap repair in Saccharomyces cerevisiae. Yeast 29, 323-334. https://doi.org/10.1002/yea.2912

Fredrickson, E.K., Gallagher, P.S., Clowes Candadai, S.V., Gardner, R.G., 2013. Substrate recognition in nuclear protein quality control degradation is governed by exposed hydrophobicity that correlates with aggregation and insolubility. J Biol Chem 288, 61306139. https://doi.org/10.1074/jbc.M112.406710

Gallagher, P.S., Clowes Candadai, S.V., Gardner, R.G., 2014. The requirement for Cdc48/p97 in nuclear protein quality control degradation depends on the substrate and correlates with substrate insolubility. Journal of Cell Science 127, 1980-1991. https://doi.org/10.1242/jcs. 141838

Gardner, R.G., Nelson, Z.W., Gottschling, D.E., 2005. Degradation-mediated protein quality control in the nucleus. Cell 120, 803-815. https://doi.org/10.1016/j.cell.2005.01.016

Geffen, Y., Appleboim, A., Gardner, R.G., Friedman, N., Sadeh, R., Ravid, T., 2016. Mapping the Landscape of a Eukaryotic Degronome. Mol. Cell 63, 1055-1065. https://doi.org/10.1016/j.molcel.2016.08.005

Gersing, S.K., Wang, Y., Grønbæk-Thygesen, M., Kampmeyer, C., Clausen, L., Willemoës, M., Andréasson, C., Stein, A., Lindorff-Larsen, K., Hartmann-Petersen, R., 2021. Mapping the degradation pathway of a disease-linked aspartoacylase variant. PLOS Genetics 17, e1009539. https://doi.org/10.1371/journal.pgen.1009539

Gietz, R.D., Schiestl, R.H., 2007. High-efficiency yeast transformation using the LiAc/SS carrier DNA/PEG method. Nat Protoc 2, 31-34. https://doi.org/10.1038/nprot.2007.13

Gilon, T., Chomsky, O., Kulka, R.G., 1998. Degradation signals for ubiquitin system proteolysis in $\begin{array}{lllll}\text { Saccharomyces } & \text { cerevisiae. } & \text { EMBO }\end{array}$ https://doi.org/10.1093/emboj/17.10.2759

Gowda, N.K.C., Kaimal, J.M., Kityk, R., Daniel, C., Liebau, J., Öhman, M., Mayer, M.P., Andréasson, C., 2018. Nucleotide exchange factors Fes1 and HspBP1 mimic substrate to release misfolded proteins from Hsp70. Nat. Struct. Mol. Biol. 25, 83-89. https://doi.org/10.1038/s41594-017-0008-2

Gowda, N.K.C., Kandasamy, G., Froehlich, M.S., Dohmen, R.J., Andréasson, C., 2013. Hsp70 nucleotide exchange factor Fes1 is essential for ubiquitin-dependent degradation of misfolded cytosolic proteins. PNAS 110, 5975-5980. https://doi.org/10.1073/pnas.1216778110

Guerriero, C.J., Weiberth, K.F., Brodsky, J.L., 2013. Hsp70 targets a cytoplasmic quality control substrate to the Sanlp ubiquitin ligase. J. Biol. Chem. 288, 18506-18520. https://doi.org/10.1074/jbc.M113.475905

Guharoy, M., Bhowmick, P., Sallam, M., Tompa, P., 2016a. Tripartite degrons confer diversity and specificity on regulated protein degradation in the ubiquitin-proteasome system. Nat Commun 7, 10239. https://doi.org/10.1038/ncomms 10239

Guharoy, M., Bhowmick, P., Tompa, P., 2016b. Design Principles Involving Protein Disorder Facilitate Specific Substrate Selection and Degradation by the Ubiquitin-Proteasome System. J Biol Chem 291, 6723-6731. https://doi.org/10.1074/jbc.R115.692665 
Heck, J.W., Cheung, S.K., Hampton, R.Y., 2010. Cytoplasmic protein quality control degradation mediated by parallel actions of the E3 ubiquitin ligases Ubr1 and San1. Proc. Natl. Acad. Sci. U.S.A. 107, 1106-1111. https://doi.org/10.1073/pnas.0910591107

Hickey, C.M., Breckel, C., Zhang, M., Theune, W.C., Hochstrasser, M., 2021. Protein quality control degron-containing substrates are differentially targeted in the cytoplasm and nucleus by ubiquitin ligases. Genetics 217, 1-19. https://doi.org/10.1093/genetics/iyaa031

Höhfeld, J., Jentsch, S., 1997. GrpE-like regulation of the Hsc70 chaperone by the anti-apoptotic protein BAG-1. The EMBO Journal 16, 6209-6216. https://doi.org/10.1093/emboj/16.20.6209

Houben, B., Michiels, E., Ramakers, M., Konstantoulea, K., Louros, N., Verniers, J., van der Kant, R., De Vleeschouwer, M., Chicória, N., Vanpoucke, T., Gallardo, R., Schymkowitz, J., Rousseau, F., 2020. Autonomous aggregation suppression by acidic residues explains why chaperones favour basic residues. EMBO J. e102864. https://doi.org/10.15252/embj.2019102864

Johnson, P.R., Swanson, R., Rakhilina, L., Hochstrasser, M., 1998. Degradation Signal Masking by Heterodimerization of MAT $\alpha 2$ and MATa1 Blocks Their Mutual Destruction by the Ubiquitin-Proteasome Pathway. Cell 94, 217-227. https://doi.org/10.1016/S00928674(00)81421-X

Jones, R.D., Enam, C., Ibarra, R., Borror, H.R., Mostoller, K.E., Fredrickson, E.K., Lin, J., Chuang, E., March, Z., Shorter, J., Ravid, T., Kleiger, G., Gardner, R.G., 2020. The extent of Ssa1/Ssa2 Hsp70 chaperone involvement in nuclear protein quality control degradation varies with the substrate. Mol. Biol. Cell 31, 221-233. https://doi.org/10.1091/mbc.E18-02-0121

Kaimal, J.M., Kandasamy, G., Gasser, F., Andréasson, C., 2017. Coordinated Hsp110 and Hsp104 Activities Power Protein Disaggregation in Saccharomyces cerevisiae. Mol Cell Biol 37, e00027-17. https://doi.org/10.1128/MCB.00027-17

Kampmeyer, C., Larsen-Ledet, S., Wagnkilde, M.R., Michelsen, M., Iversen, H.K.M., Nielsen, S.V., Lindemose, S., Caregnato, A., Ravid, T., Stein, A., Teilum, K., Lindorff-Larsen, K., Hartmann-Petersen, R., 2021. Disease-linked mutations trigger exposure of a protein quality control degron in the DHFR protein (preprint). bioRxiv. https://doi.org/10.1101/2021.11.04.467226

Kandasamy, G., Andréasson, C., 2018. Hsp70-Hsp110 chaperones deliver ubiquitin-dependent and independent substrates to the $26 \mathrm{~S}$ proteasome for proteolysis in yeast. J. Cell. Sci. 131 . https://doi.org/10.1242/jcs.210948

Kohler, V., Andréasson, C., 2020. Hsp70-mediated quality control: should I stay or should I go? Biol Chem 401, 1233-1248. https://doi.org/10.1515/hsz-2020-0187

Koopman, M.B., Rüdiger, S.G., 2020. Behind closed gates - chaperones and charged residues determine protein fate. EMBO J 39, e104939. https://doi.org/10.15252/embj.2020104939

Koren, I., Timms, R.T., Kula, T., Xu, Q., Li, M.Z., Elledge, S.J., 2018. The Eukaryotic Proteome Is Shaped by E3 Ubiquitin Ligases Targeting C-Terminal Degrons. Cell 173, 1622-1635.e14. https://doi.org/10.1016/j.cell.2018.04.028

Kriegenburg, F., Jakopec, V., Poulsen, E.G., Nielsen, S.V., Roguev, A., Krogan, N., Gordon, C., Fleig, U., Hartmann-Petersen, R., 2014. A Chaperone-Assisted Degradation Pathway Targets Kinetochore Proteins to Ensure Genome Stability. PLOS Genetics 10, e1004140. https://doi.org/10.1371/journal.pgen.1004140

Kuipers, B.J.H., Gruppen, H., 2007. Prediction of Molar Extinction Coefficients of Proteins and Peptides Using UV Absorption of the Constituent Amino Acids at $214 \mathrm{~nm}$ To Enable Quantitative Reverse Phase High-Performance Liquid Chromatography-Mass Spectrometry Analysis. J. Agric. Food Chem. 55, 5445-5451. https://doi.org/10.1021/jf0703371 
Kwon, Y.T., Ciechanover, A., 2017. The Ubiquitin Code in the Ubiquitin-Proteasome System and Autophagy. Trends Biochem Sci 42, 873-886. https://doi.org/10.1016/j.tibs.2017.09.002

Liu, J., Tokheim, C., Lee, J.D., Gan, W., North, B.J., Liu, X.S., Pandolfi, P.P., Wei, W., 2021. Genetic fusions favor tumorigenesis through degron loss in oncogenes. Nat Commun 12, 6704. https://doi.org/10.1038/s41467-021-26871-y

Macossay-Castillo, M., Marvelli, G., Guharoy, M., Jain, A., Kihara, D., Tompa, P., Wodak, S.J., 2019. The Balancing Act of Intrinsically Disordered Proteins: Enabling Functional Diversity while Minimizing Promiscuity. Journal of Molecular Biology 431, 1650-1670. https://doi.org/10.1016/j.jmb.2019.03.008

Martin, M., 2011. Cutadapt removes adapter sequences from high-throughput sequencing reads. EMBnet.journal 17, 10-12. https://doi.org/10.14806/ej.17.1.200

Maurer, M.J., Spear, E.D., Yu, A.T., Lee, E.J., Shahzad, S., Michaelis, S., 2016. Degradation Signals for Ubiquitin-Proteasome Dependent Cytosolic Protein Quality Control (CytoQC) in Yeast. G3 (Bethesda) 6, 1853-1866. https://doi.org/10.1534/g3.116.027953

McCarty, J.S., Buchberger, A., Reinstein, J., Bukau, B., 1995. The role of ATP in the functional cycle of the DnaK chaperone system. J. Mol. Biol. 249, 126-137. https://doi.org/10.1006/jmbi.1995.0284

Mészáros, B., Erdos, G., Dosztányi, Z., 2018. IUPred2A: context-dependent prediction of protein disorder as a function of redox state and protein binding. Nucleic Acids Res 46, W329-W337. https://doi.org/10.1093/nar/gky384

Montgomery, D.L., Morimoto, R.I., Gierasch, L.M., 1999. Mutations in the substrate binding domain of the Escherichia coli $70 \mathrm{kda}$ molecular chaperone, DnaK, which alter substrate affinity or interdomain coupling11Edited by M. Gottesman. Journal of Molecular Biology 286, 915932. https://doi.org/10.1006/jmbi.1998.2514

Nordquist, E.B., English, C.A., Clerico, E.M., Sherman, W., Gierasch, L.M., Chen, J., 2021. Physicsbased modeling provides predictive understanding of selectively promiscuous substrate binding by Hsp70 chaperones. PLOS Computational Biology 17, e1009567. https://doi.org/10.1371/journal.pcbi.1009567

Oh, E., Akopian, D., Rape, M., 2018. Principles of Ubiquitin-Dependent Signaling. Annu. Rev. Cell Dev. Biol. 34, 137-162. https://doi.org/10.1146/annurev-cellbio-100617-062802

Pfleger, C.M., Kirschner, M.W., 2000. The KEN box: an APC recognition signal distinct from the D box targeted by Cdh1. Genes Dev 14, 655-665.

Poewe, W., Seppi, K., Tanner, C.M., Halliday, G.M., Brundin, P., Volkmann, J., Schrag, A.-E., Lang, A.E., 2017. Parkinson disease. Nat Rev Dis Primers 3, 1-21. https://doi.org/10.1038/nrdp.2017.13

Pohl, C., Dikic, I., 2019. Cellular quality control by the ubiquitin-proteasome system and autophagy. Science 366, 818-822. https://doi.org/10.1126/science.aax3769

Powers, E.T., Gierasch, L.M., 2021. The Proteome Folding Problem and Cellular Proteostasis. J Mol Biol 167197. https://doi.org/10.1016/j.jmb.2021.167197

Ravid, T., Kreft, S.G., Hochstrasser, M., 2006. Membrane and soluble substrates of the Doa10 ubiquitin ligase are degraded by distinct pathways. EMBO J 25, 533-543. https://doi.org/10.1038/sj.emboj.7600946

Rebeaud, M.E., Mallik, S., Goloubinoff, P., Tawfik, D.S., 2021. On the evolution of chaperones and cochaperones and the expansion of proteomes across the Tree of Life. Proc Natl Acad Sci U S A 118, e2020885118. https://doi.org/10.1073/pnas.2020885118

Rosenzweig, R., Nillegoda, N.B., Mayer, M.P., Bukau, B., 2019. The Hsp70 chaperone network. Nat. Rev. Mol. Cell Biol. 20, 665-680. https://doi.org/10.1038/s41580-019-0133-3 
Rousseau, F., Serrano, L., Schymkowitz, J.W.H., 2006. How Evolutionary Pressure Against Protein Aggregation Shaped Chaperone Specificity. Journal of Molecular Biology 355, 1037-1047. https://doi.org/10.1016/j.jmb.2005.11.035

Rüdiger, S., Germeroth, L., Schneider-Mergener, J., Bukau, B., 1997. Substrate specificity of the DnaK chaperone determined by screening cellulose-bound peptide libraries. EMBO J. 16, 1501-1507. https://doi.org/10.1093/emboj/16.7.1501

Samant, R.S., Livingston, C.M., Sontag, E.M., Frydman, J., 2018. Distinct proteostasis circuits cooperate in nuclear and cytoplasmic protein quality control. Nature 563, 407-411. https://doi.org/10.1038/s41586-018-0678-X

Schmid, D., Baici, A., Gehring, H., Christen, P., 1994. Kinetics of molecular chaperone action. Science 263, 971-973. https://doi.org/10.1126/science.8310296

Schmid, D., Jaussi, R., Christen, P., 1992. Precursor of mitochondrial aspartate aminotransferase synthesized in Escherichia coli is complexed with heat-shock protein DnaK. Eur J Biochem 208, 699-704. https://doi.org/10.1111/j.1432-1033.1992.tb17237.x

Shiber, A., Breuer, W., Brandeis, M., Ravid, T., 2013. Ubiquitin conjugation triggers misfolded protein sequestration into quality control foci when Hsp70 chaperone levels are limiting. Mol Biol Cell 24, 2076-2087. https://doi.org/10.1091/mbc.E13-01-0010

Singh, A., Vashistha, N., Heck, J., Tang, X., Wipf, P., Brodsky, J.L., Hampton, R.Y., 2020. Direct involvement of Hsp70 ATP hydrolysis in Ubr1-dependent quality control. MBoC 31, 26692686. https://doi.org/10.1091/mbc.E20-08-0541

Summers, D.W., Wolfe, K.J., Ren, H.Y., Cyr, D.M., 2013. The Type II Hsp40 Sis1 Cooperates with Hsp70 and the E3 Ligase Ubr1 to Promote Degradation of Terminally Misfolded Cytosolic Protein. PLoS One 8, e52099. https://doi.org/10.1371/journal.pone.0052099

Timms, R.T., Koren, I., 2020. Tying up loose ends: the N-degron and C-degron pathways of protein degradation. Biochem Soc Trans 48, 1557-1567. https://doi.org/10.1042/BST20191094

Tokheim, C., Wang, X., Timms, R.T., Zhang, B., Mena, E.L., Wang, B., Chen, C., Ge, J., Chu, J., Zhang, W., Elledge, S.J., Brown, M., Liu, X.S., 2021. Systematic characterization of mutations altering protein degradation in human cancers. Molecular Cell 81, 1292-1308.e11. https://doi.org/10.1016/j.molcel.2021.01.020

Varshavsky, A., 2011. The N-end rule pathway and regulation by proteolysis. Protein Sci 20, 12981345. https://doi.org/10.1002/pro.666

Varshavsky, A., 1991. Naming a targeting signal. Cell 64, 13-15. https://doi.org/10.1016/00928674(91)90202-a

Zhang, P., Leu, J.I.-J., Murphy, M.E., George, D.L., Marmorstein, R., 2014. Crystal structure of the stress-inducible human heat shock protein 70 substrate-binding domain in complex with peptide substrate. PLoS One 9, e103518. https://doi.org/10.1371/journal.pone.0103518

Zhu, X., Zhao, X., Burkholder, W.F., Gragerov, A., Ogata, C.M., Gottesman, M.E., Hendrickson, W.A., 1996. Structural analysis of substrate binding by the molecular chaperone DnaK. Science 272, 1606-1614. https://doi.org/10.1126/science.272.5268.1606

Zhuravleva, A., Gierasch, L.M., 2015. Substrate-binding domain conformational dynamics mediate Hsp70 allostery. PNAS 112, E2865-E2873. 


\section{Figure legends}

Figure 1 Growth-based selection for degron sequences. (A) A schematic representation of the Ura3HA-GFP reporter system. In-frame fusion of degrons to the C-terminus of the reporter will lead to proteasomal degradation (Pac-Man) leading to a 5-FOA resistant phenotype. (B) As a proof of principle for the reporter system, the growth of wild-type cells expressing the reporter vector with and without fusion to the CL1 degron was compared by dilutions on solid media. Note that the growth defect of the CL1 strain on media without uracil is suppressed by the addition of the proteasome inhibitor bortezomib (BZ), while in the presence of 5-FOA, the CL1 strain is able to form colonies. (C) Analysis of protein levels in vector or CL1 cells after 4 hours of bortezomib (BZ) treatment by SDS-PAGE and Western blotting, using antibodies to the HA-tag in the reporter. Blotting against Pgk1 served as loading control. (D) Schematic overview of the library construction. Three primer pairs were designed to cover the pTR1412 vector, encoding the Ura3-HA-GFP-reporter. Four amino acid positions in the shown C-terminal peptide were randomized by using a primer carrying TriMix 20 at the bold-faced positions marked X. PCR amplification yielded three partially overlapping fragments, which were assembled by gap repair following transformation into yeast. (E) Schematic overview of degron selection from the peptide library. Transformants were selected on media without leucine (-LEU) and harvested to form a library stock. An overnight culture of the library was then plated on media with 5-FOA (-LEU+5-FOA) to select for degrons, and harvested after 48 hours. Finally, DNA was extracted and sequenced.

Figure 2 Analyses of selected degrons. (A) Prevalence of amino acids at screened positions 1-4 in the $10 \%$ most occurring sequences in the 5-FOA-treated library $(+)$ and untreated library (-). Amino acids are grouped into hydrophobic (Ala, Ile, Leu, Met, Phe, Val, Pro, Gly, Trp, Tyr), negative (Asp, 
Glu), polar (Gln, Asn, His, Ser, Thr, Cys) and positive (Arg, Lys) residues. (B) The ten most prevalent sequences in the 5-FOA-treated library are listed along with the enrichment scores. (C) The growth of the ten most prevalent sequences from the 5-FOA library was compared on solid media. (D) The constructs from panel B were transformed into a temperature-sensitive (ts) Hsp110-double mutant strain, sse1-200sse $2 \Delta$, and the protein levels at the permissive temperature $\left(25^{\circ} \mathrm{C}\right)$ and restrictive temperature $\left(30^{\circ} \mathrm{C}\right)$ were compared by SDS-PAGE and Western blotting using antibodies to the HA tag. Blotting against tubulin served as a loading control.

Figure 3 Investigation of the degron capacity of the canonical Hsp70-binding motif, RLLL. (A) Structure of the Hsp70 substrate-binding domain (SBD) (blue) in complex with the Hsp70-binding peptide, NRLLLTG (red) (PDB: 4PO2) (Zhang et al., 2014). (B) Illustration of APPY-variants fused in one, two or three copies to the Ura3-HA-GFP-reporter. From the literature (Rüdiger et al., 1997), we predicted strong (RLLL), intermediate (RAAA) and weak (DAAA) degron motifs. (C) Cells carrying the indicated fusions were analyzed by microscopy for GFP fluorescence. Bar, $10 \mu \mathrm{m}$. (D) Cell lysates of cells carrying the constructs listed in panel (B) were prepared and compared by SDSPAGE and Western blotting using antibodies to the HA-tag. Tubulin served as loading control. (E) Analysis of the indicated protein levels by SDS-PAGE and Western blotting from cells treated with the translation inhibitor cycloheximide ( $\mathrm{CHX}$ ) (left panel) or the proteasome inhibitor bortezomib (BZ) (right panel). Pgk1 served as loading control. (F) Growth assay of cells with the indicated Cterminal fusions.

Figure 4 Components involved in targeting the RLLL degron for degradation. (A) Myc-tagged Ssa1 (Hsp70) was co-immunoprecipitated with the indicated GFP fusions using GFP-trap resin from cultures treated with bortezomib. The precipitated protein was analyzed by SDS-PAGE and blotting 
with antibodies to myc and GFP. (B) The protein levels of the RLLL degron from cells treated (+) or untreated (-) with myricetin (MYR) for 16 hours were compared by SDS-PAGE and blotting against the HA-tag on the reporter. Tubulin served as loading control. (C) As in Figure 2D, protein levels in the temperature-sensitive (ts) Hsp110-double mutant strain at $25^{\circ} \mathrm{C}$ and $30{ }^{\circ} \mathrm{C}$ were compared by blotting against the HA-tag. Tubulin served as loading control. (DE) The protein levels of the RLLL degron were compared in the indicated yeast strains by SDS-PAGE and blotting for the HA-tag on the reporter. A Ponceau S staining of the membrane is included as loading control. (FG) The dependence of co-chaperones and E3 ligases for targeting the RLLL degron was analyzed by growth assays on solid media using the indicated null mutants. Wild-type cells transformed with the reporter vector alone were included for comparison. $(\mathrm{H})$ Schematic illustration of the proposed degradation pathway for misfolded proteins. Mutations or stress conditions increase the risk for protein misfolding leading to degron exposure. Hsp70 binds the degron motif in the misfolded protein, thus facilitating protein refolding (top) or degradation (bottom) in the presence of Ubr1 and JDPs. Ubr1-mediated ubiquitylation targets the protein for proteasomal degradation in collaboration with NEF proteins Hsp1 10 and Fes1.

Supplementary Figure S1 Raincloud plots of Limbo scores. The Limbo predictor for peptide binding to E. coli Hsp70 (DnaK) (Durme et al., 2009) was used to analyze all 18,706 sequences (red), or the top 100 sequences (blue) or the ten most prevalent sequences (green) from the 5-FOA resistant library. A high Limbo score indicates greater likelihood for binding to Hsp70.

Supplementary Figure S2 Proteome wide analysis of predicted Hsp70 binding sites. The number of residues that are both predicted to be Hsp70 binding sites and disordered, and thus solvent exposed, is different for proteins with different levels of abundance and half-life. Very low abundance proteins 
are an exception of this trend which has been suggested to reflect the absence of selection against exposed degrons when the protein concentrations are lower than the binding affinity of harmful interactions (Dubreuil et al., 2019).

Supplementary Figure S3 Analyses of solubility and flanking regions for the RLLL degron.

(A) The solubility of the reporter proteins was analyzed by fractionating cell extracts into soluble supernatant (S) and insoluble pellet (P) fractions by centrifugation. The protein levels were analyzed by SDS-PAGE and Western blotting using antibodies to the HA-tag in the reporter. Pgk1 served as a loading control for the soluble protein fractions, while Pmal served as loading control for the insoluble protein fractions. (B) Fusion of the URA3-HA-GFP-reporter to listed APPY variants induced growth phenotypes that were assessed on solid media. The RLLL motif is highlighted (bold) and amino acid substitutions are shown in red. (C) The abundance of variants from panel B was compared by SDS-PAGE and Western blotting of whole-cell lysates using antibodies to HA. Pgk1 served as a loading control. (D) The secondary structure of selected variants was analyzed by far-UV circular dichroism (CD) spectroscopy. The top panel shows molar ellipticity and the lower panel shows HT voltage.

Supplementary Figure S4 Ubr1 interacts with Ssa1. Wild-type yeast cells expressing myc-tagged Ssal and/or HA-tagged Ubr1, as indicated, were used for immunoprecipitation (IP) with myc-trap resin. The precipitated material was analyzed by SDS-PAGE and Western blotting using antibodies to myc and HA. 


\section{Supplementary Table S1}

DNA primers used in this study

\begin{tabular}{|c|c|c|}
\hline Name & Sequence & Purpose \\
\hline $\begin{array}{l}\text { F1 } \\
\text { LEU2_1119 } \\
\text { fW }\end{array}$ & $\begin{array}{l}\text { GCTGGTGATTATAATACCATT } \\
\text { TAGGTGGGTTGG }\end{array}$ & $\begin{array}{l}\text { Forward fragment } 1 \text { containing URA3-GFP } \\
\text { for library construction }\end{array}$ \\
\hline $\begin{array}{l}\text { F1_degron_ta } \\
\text { g_18_rv }\end{array}$ & $\begin{array}{l}\text { TGATTGTAACAATGCACAGG } \\
\text { ATCCTTCGTC }\end{array}$ & $\begin{array}{l}\text { Reverse fragment } 1 \text { containing URA3-GFP } \\
\text { for library construction }\end{array}$ \\
\hline $\begin{array}{l}\text { F2_degron_ta } \\
g \_f w\end{array}$ & $\begin{array}{l}\text { GACGAAGGATCCTGTGCATT } \\
\text { GTTACAATCA } \\
\text { /iTriMix20//iTriMix20//iTriMix20/ } \\
\text { /iTriMix20/ } \\
\text { TCAGCACCAAGAAGAGCTGC }\end{array}$ & $\begin{array}{l}\text { Forward fragment } 2 \text { containing a degron tag } \\
\text { including four trimer } 20 \text { codon mixes for } \\
\text { library construction }\end{array}$ \\
\hline F2_rv & $\begin{array}{l}\text { ATTACGCCAAGCTCGAAATT } \\
\text { AACCC }\end{array}$ & $\begin{array}{l}\text { Reverse fragment } 2 \text { containing a degron tag } \\
\text { for library construction }\end{array}$ \\
\hline F3_fw & $\begin{array}{l}\text { AGTGAGGGTTAATTTCGAGC } \\
\text { TTGGC }\end{array}$ & $\begin{array}{l}\text { Forward fragment } 3 \text { containing origin of } \\
\text { replication for library construction }\end{array}$ \\
\hline $\begin{array}{l}\text { F3_LEU2_73 } \\
\text { 5_rv }\end{array}$ & $\begin{array}{l}\text { CCAACCCACCTAAATGGTAT } \\
\text { TATAATCACC }\end{array}$ & $\begin{array}{l}\text { Reverse fragment } 3 \text { containing origin of } \\
\text { replication for library construction }\end{array}$ \\
\hline $\begin{array}{l}\text { Illumina_adap } \\
\text { ter_fw }\end{array}$ & $\begin{array}{l}\text { TCGTCGGCAGCGTCAGATGT } \\
\text { GTATAAGAGACAG } \\
\text { cctacgatcgacgaagg }\end{array}$ & $\begin{array}{l}\text { Forward containing degron tag for library } \\
\text { sequencing }\end{array}$ \\
\hline $\begin{array}{l}\text { Illumina_adap } \\
\text { ter_rv }\end{array}$ & $\begin{array}{l}\text { GTCTCGTGGGCTCGGAGATG } \\
\text { TGTATAAGAGACAG } \\
\text { tgtggaattgtgagcggata }\end{array}$ & $\begin{array}{l}\text { Reverse containing degron tag for library } \\
\text { sequencing }\end{array}$ \\
\hline
\end{tabular}


bioRxiv preprint doi: https://doi.org/10.1101/2021.12.22.473789; this version posted December 22, 2021. The copyright holder for this

preprint (which was not certified by peer review) is the author/funder, who has granted bioRxiv a license to display the preprint in

Figure 1

A perpetuity. It is made available under aCC-BY-NC-ND 4.0 International license.

B

\begin{tabular}{|l|l|l|}
\hline Ura3 & $\mathbb{1}$ & GFP \\
\hline
\end{tabular}

B

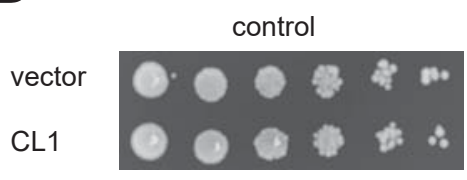

$+5 \mathrm{FOA}$

vector

CL1

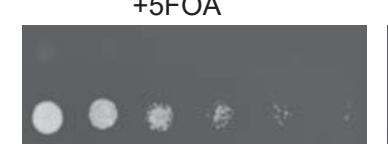

C

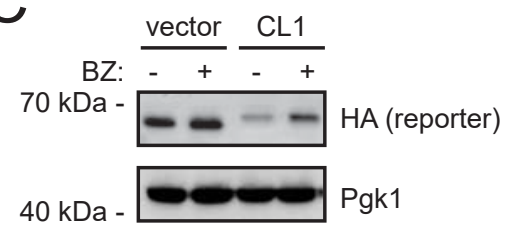

$E$

Constructing the library not a degron, not degraded, Ura3 positive, growth independent of uracil, 5FOA sensitive

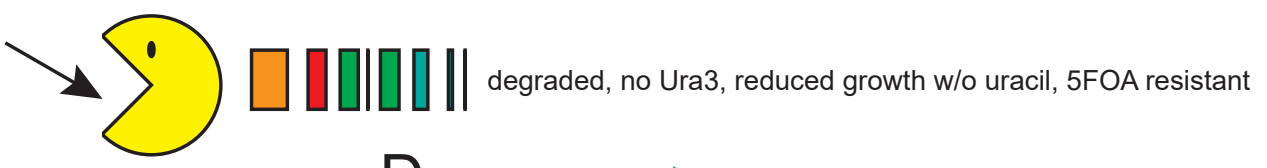

$\mathrm{D}$

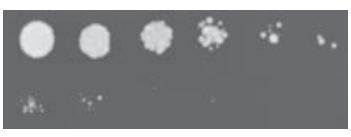

-uracil +BZ

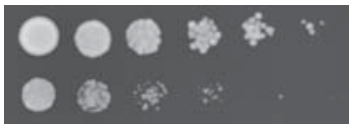

in vivo

gap repair
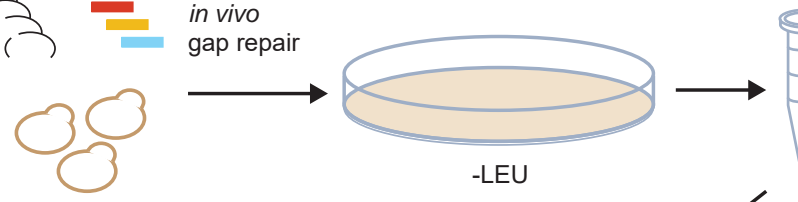

library

stock

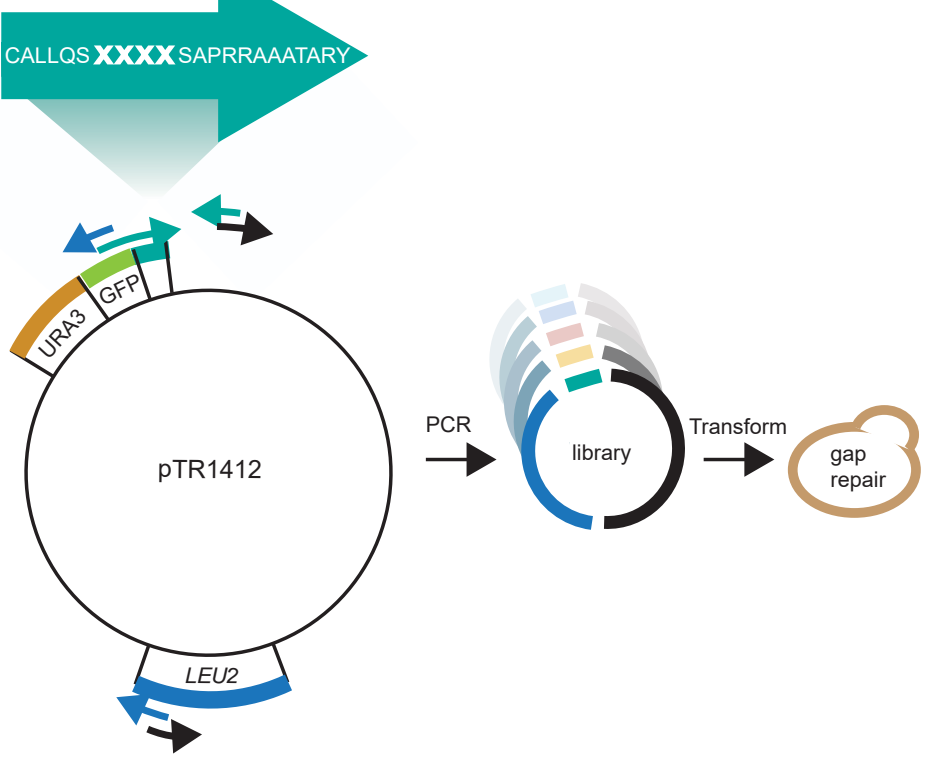

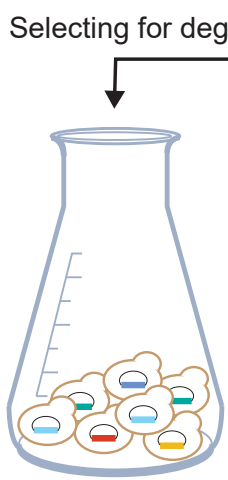

-LEU

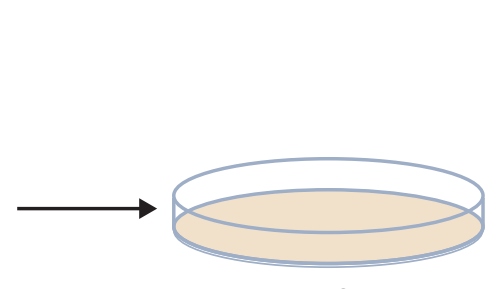

-LEU +5FOA 48 hrs

\section{ms}


bioRxiv preprint doi: https://doi.org/10.1101/2021.12.22.473789; this version posted December 22, 2021. The copyright holder for this preprint (which was not certified by peer review) is the author/funder, who has granted bioRxiv a license to display the preprint in

Figure 2 perpetuity. It is made available under aCC-BY-NC-ND 4.0 International license.

A

Position 1 Position 2 Position 3 Position 4

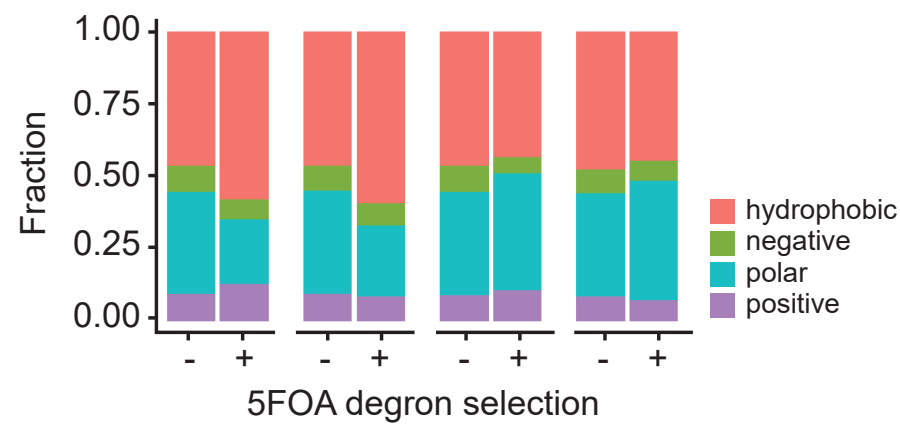

C

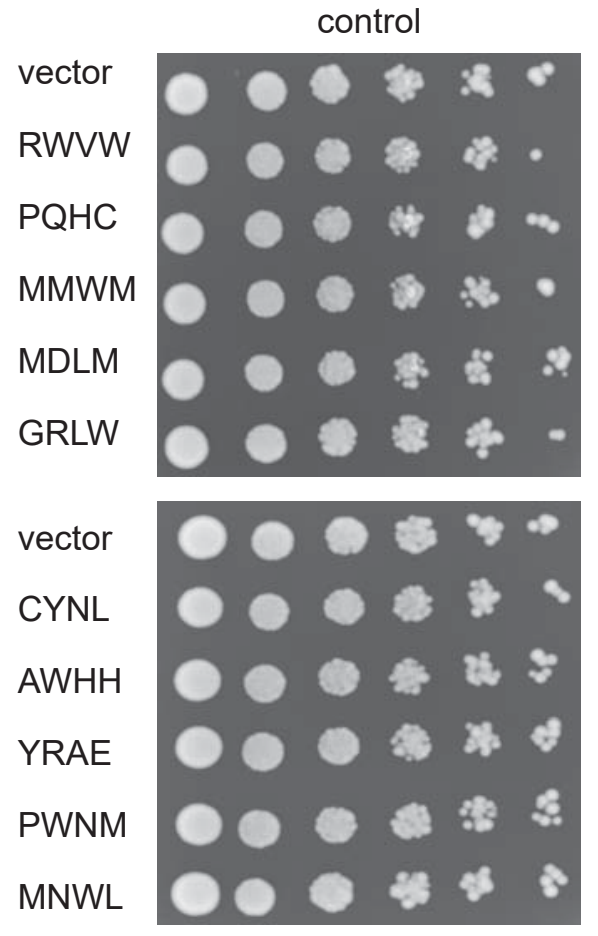

$\mathrm{D}$
B

Top 10 hits from screen

\begin{tabular}{|l|l|}
\hline Degron sequence & Enrichment score (fold) \\
\hline RWVW & 41814 \\
\hline PQHC & 35438 \\
\hline MMWM & 35035 \\
\hline MDLM & 31117 \\
\hline GRLW & 30829 \\
\hline CYNL & 28162 \\
\hline AWHH & 27032 \\
\hline YRAE & 26881 \\
\hline PWNM & 26045 \\
\hline MNWL & 25673 \\
\hline
\end{tabular}
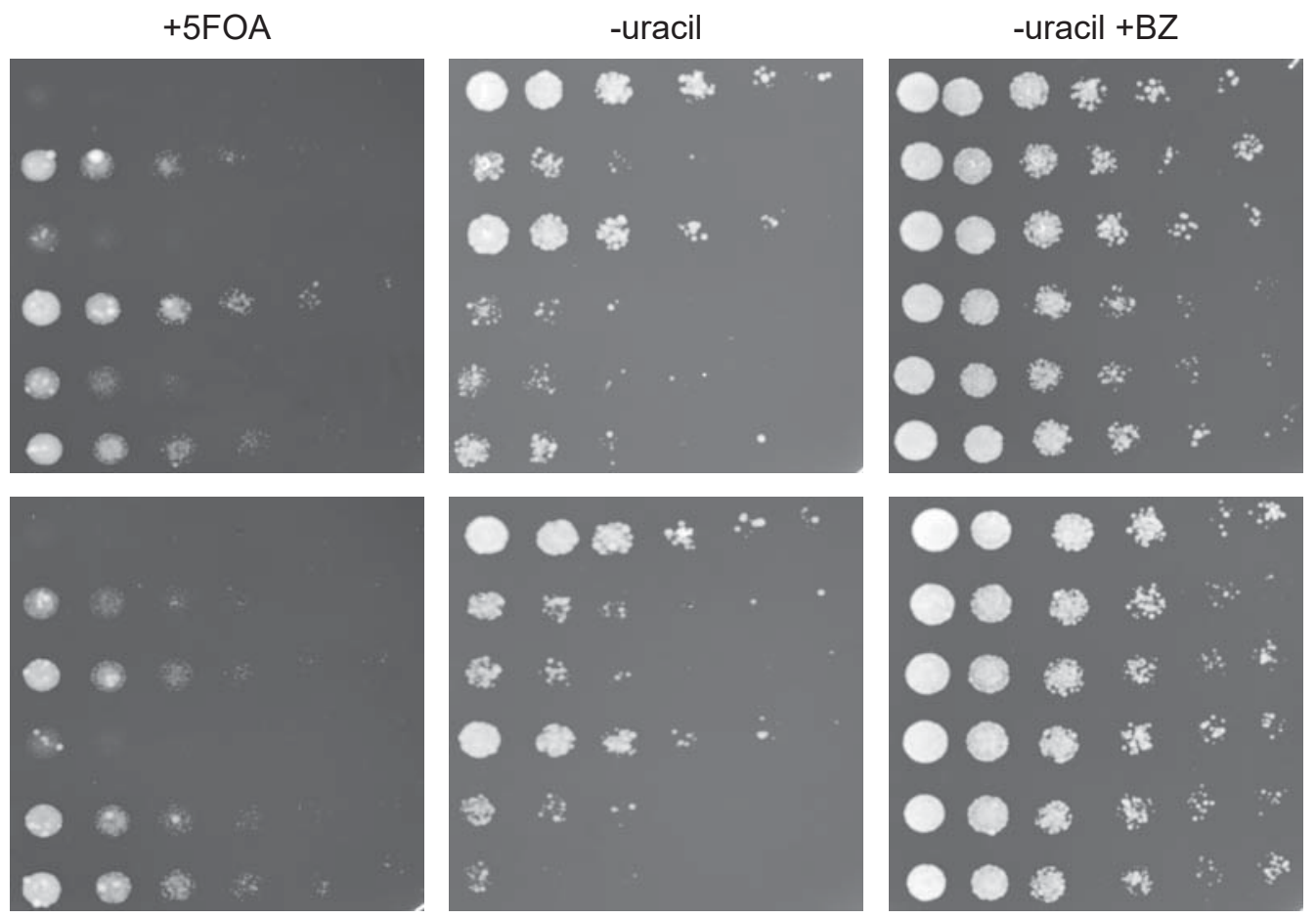

sse $1-200$ sse $2 \Delta$ (ts)

Temp. $\left({ }^{\circ} \mathrm{C}\right): \frac{\text { RWVW }}{2530} \frac{\text { PQHC }}{2530} \frac{\text { MMWM }}{2530} \frac{\text { MDLM }}{2530} \frac{\text { GRLW }}{2530} \frac{\text { CYNL }}{2530} \frac{\text { AWHH }}{2530} \frac{\text { YRAE }}{2530} \frac{\text { PWNM }}{2530} \frac{\text { MNWL }}{2530}$

$70 \mathrm{kDa}$ -

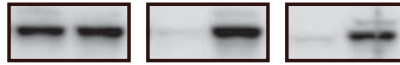
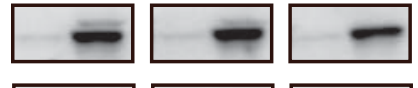

$-\cdots$

$-$

$\cdots H A$

$55 \mathrm{kDa}$
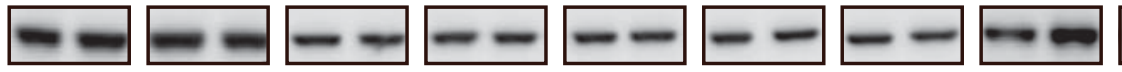

perpetuity. It is made available under aCC-BY-NC-ND 4.0 International license.

A

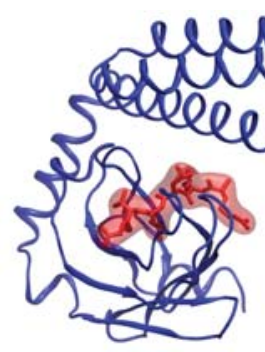

Hsp70 SBD

NRLLLTG

C
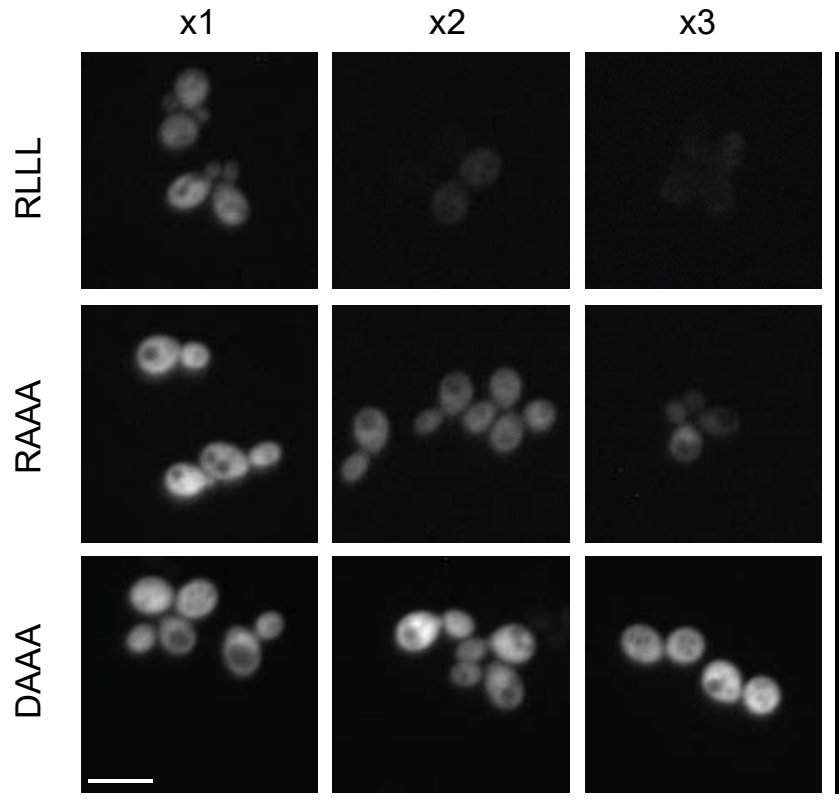

D

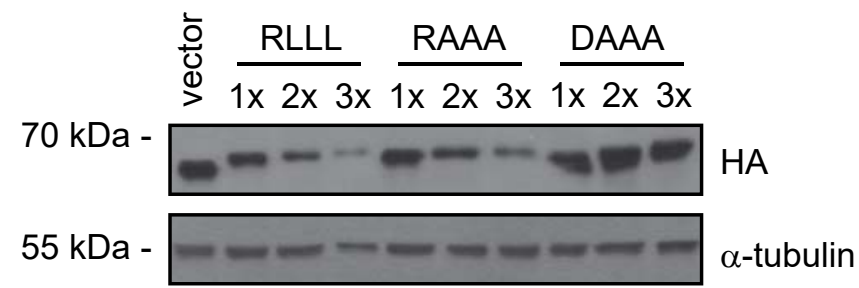

B

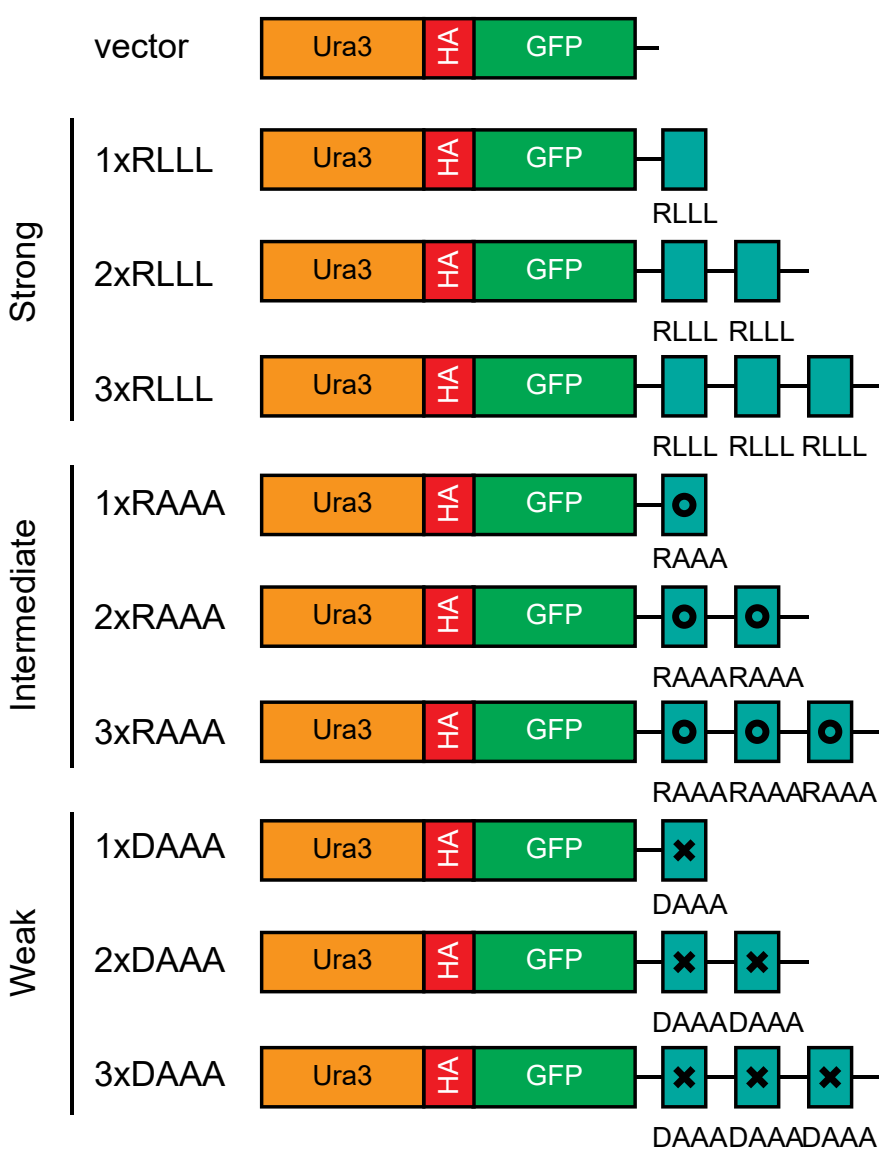

$E$

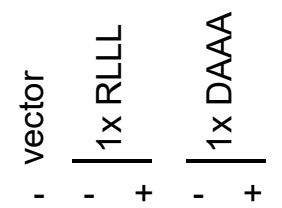

$70 \mathrm{kDa}-$

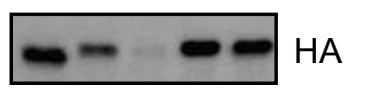

$40 \mathrm{kDa}$

-uracil

$+5 \mathrm{FOA}$

$\mathrm{F}$

control

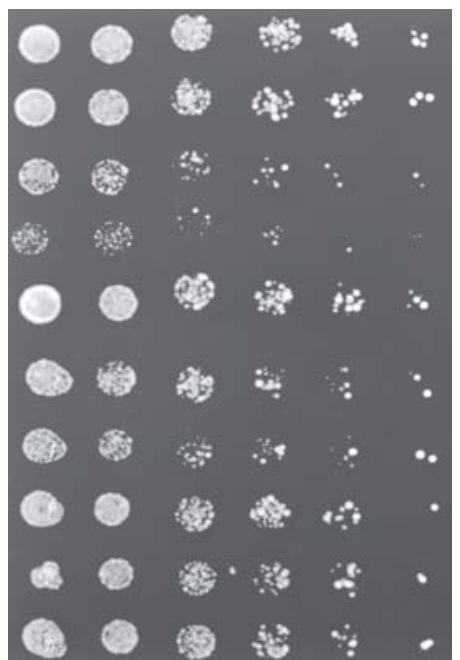
1xRLLL $2 \times R L L L$ $3 x R L L L$ 1XRAAA 2xRAAA 3xRAAA 1xDAAA 2xDAAA 3xDAAA
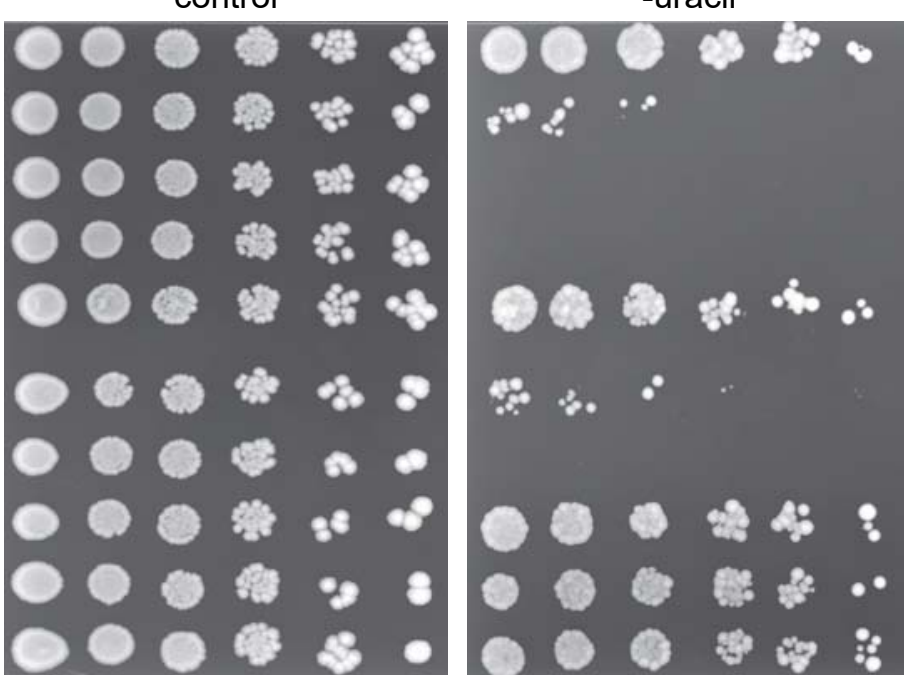

000 \& 8 
Figure 4 perpetuity. It is made available under aCC-BY-NC-ND 4.0 International license.

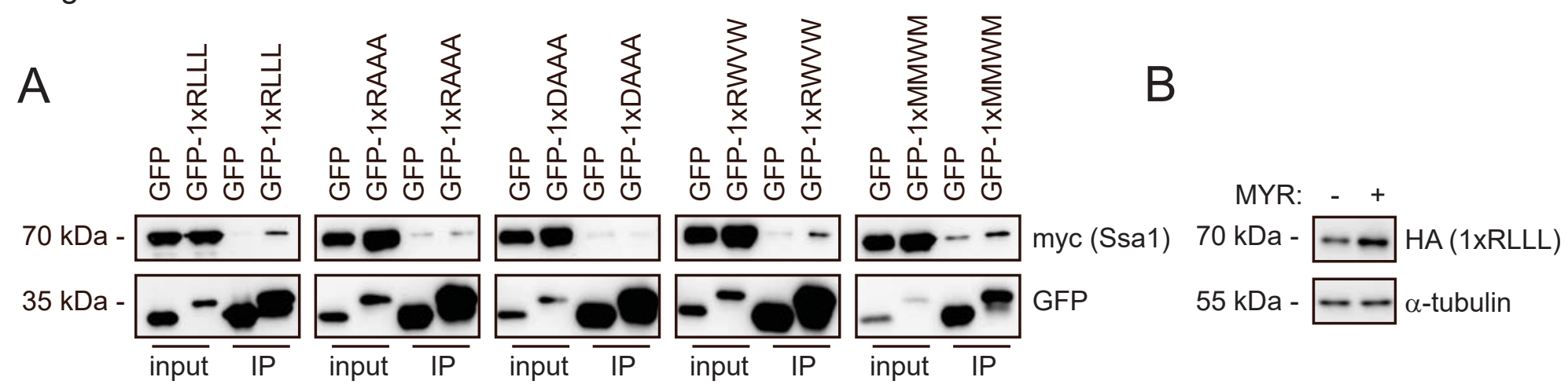

C

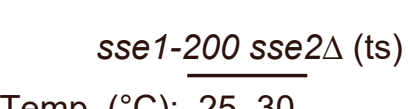

Temp. $\left({ }^{\circ} \mathrm{C}\right): 2530$

$70 \mathrm{kDa}-$

$-\infty \mathrm{HA}$

$\mathrm{HA}(1 \mathrm{xRLLL}) 70 \mathrm{kDa}-$

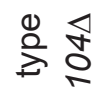

D

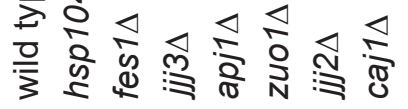

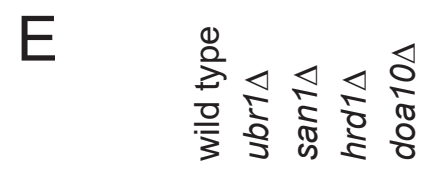

$55 \mathrm{kDa}-$

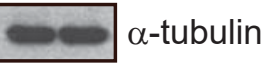

$40 \mathrm{kDa}-$

$-\infty-\infty$

HA (1xRLLL)

$70 \mathrm{kDa}-$

- - - -

HA (1xRLLL)

F

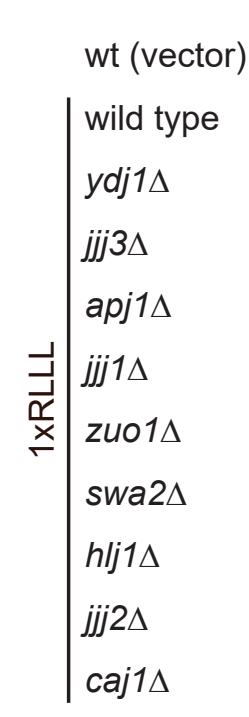

G

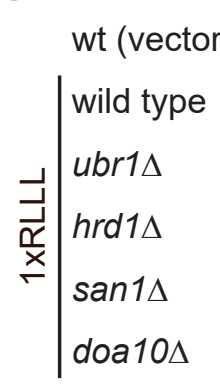

control

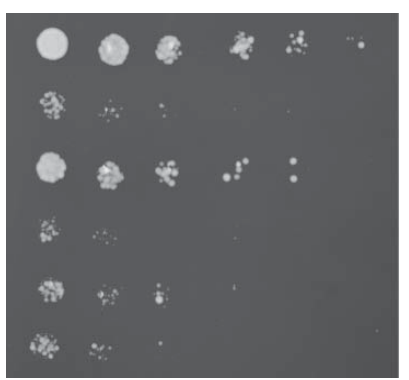

-uracil

$\mathrm{H}$
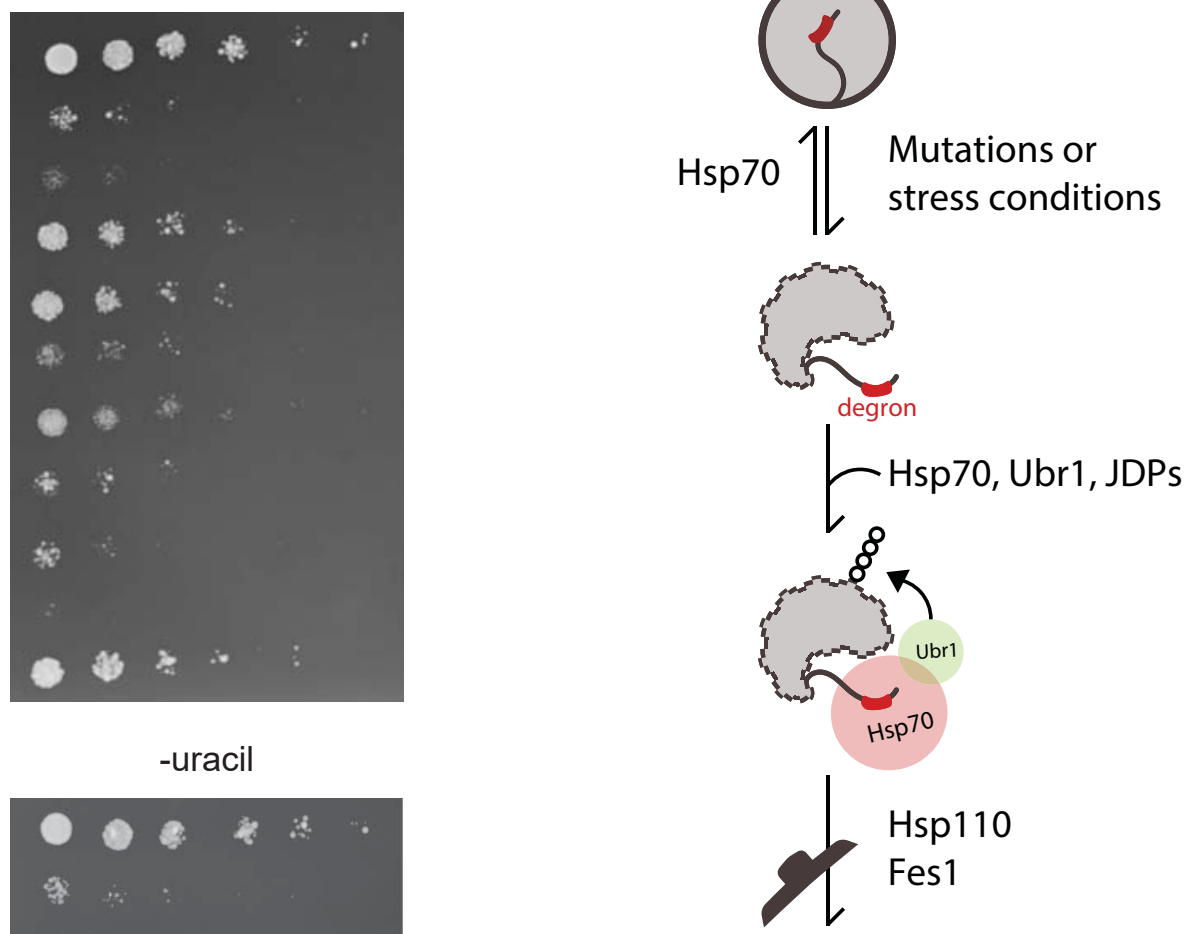

III

26S Proteasome 
bioRxiv preprint doi: https://doi.org/10.1101/2021.12.22.473789; this version posted December 22, 2021. The copyright holder for this preprint (which was not certified by peer review) is the author/funder, who has granted bioRxiv a license to display the preprint in perpetuity. It is made available under aCC-BY-NC-ND 4.0 International license.

Figure S1

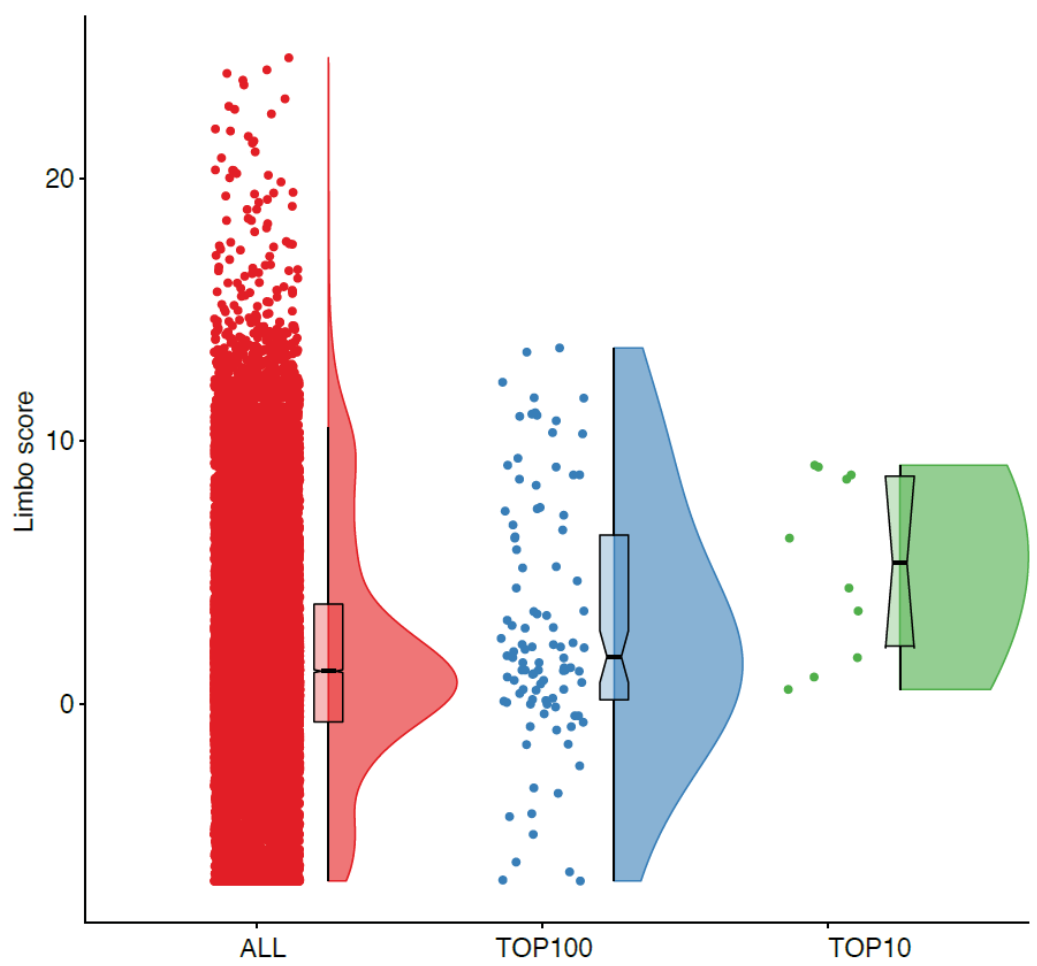


Figure S2

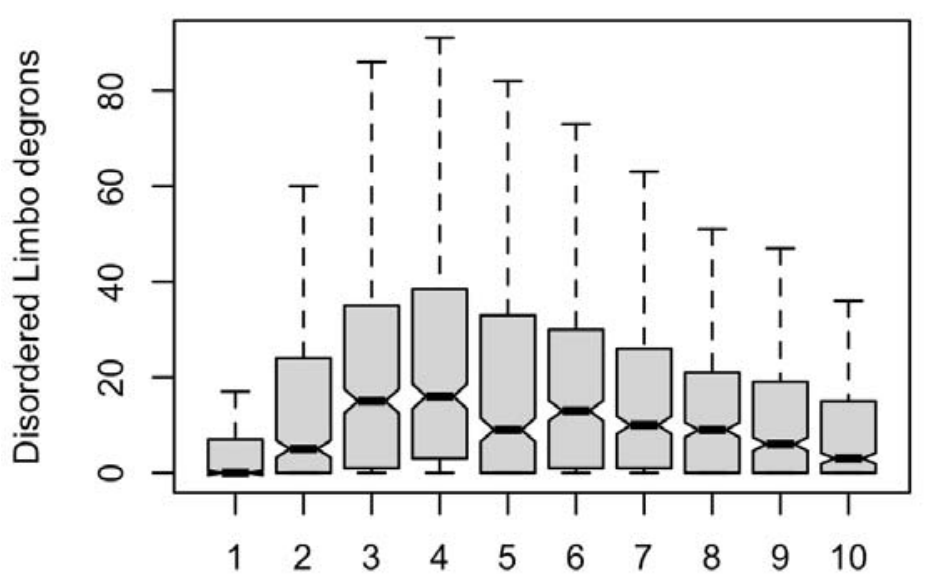

Abundance bin

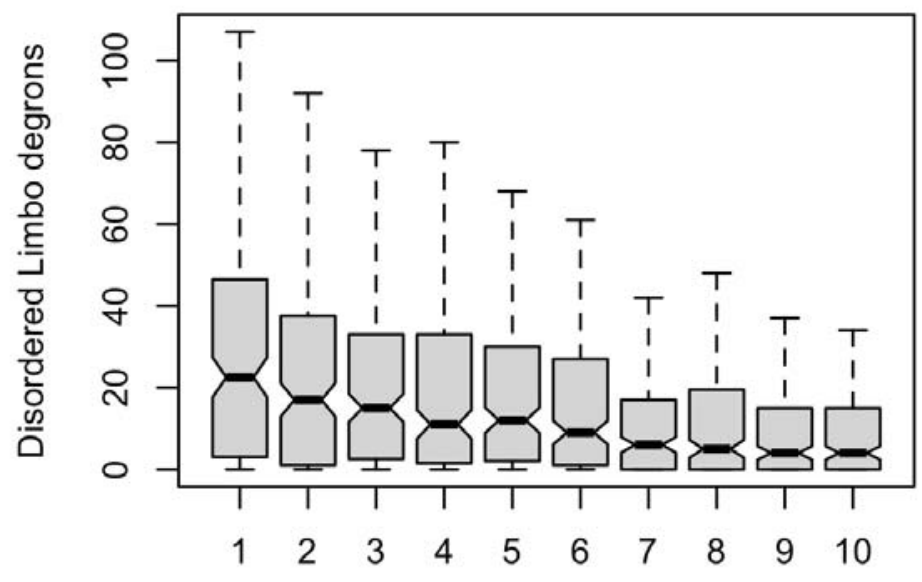

Half-life bin 
A

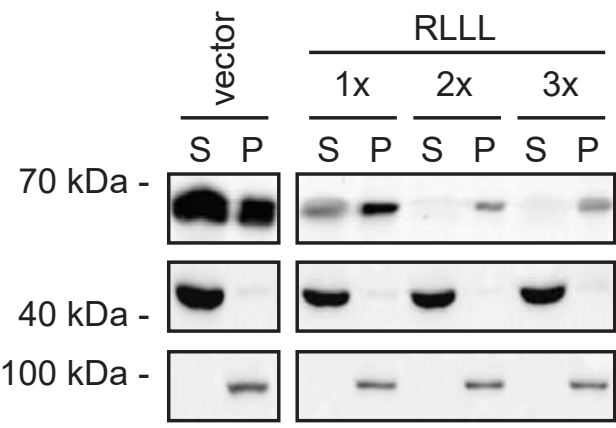
perpetuity. It is made available under aCC-BY-NC-ND 4.0 International license.

B

vector -

1XRLLL CALLQSRLLLSAPRRAAATARY 1XDAAA CALLQSDAAASAPRRAAATARY Variant1 CAAAQSRLLLSAPDDAAATARY Variant2 ATQLCSRLLLAYRRPAASALAR Variant3 CALLQSDLLLSAPRRAAATARY Variant4 CALLQSLLLRSAPRRAAATARY Variant5 CALLQSAAADSAPRRAAATARY Variant6 YRATAAARRPASLLLRSQLLAC

C

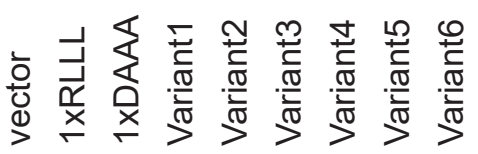

$70 \mathrm{kDa}-$

$40 \mathrm{kDa}-$

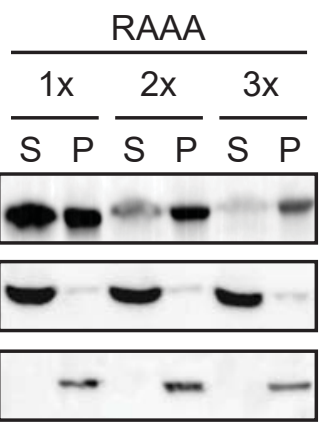

control

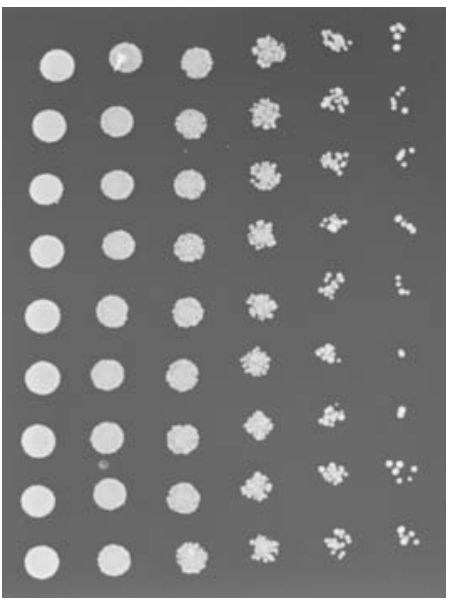

DAAA

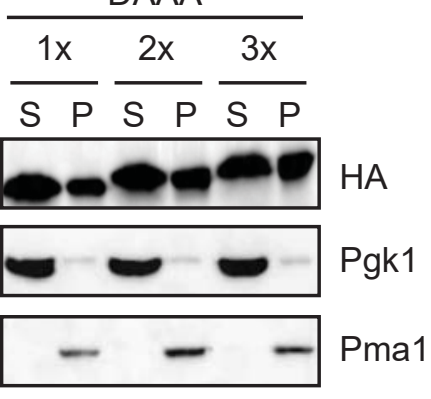

-uracil

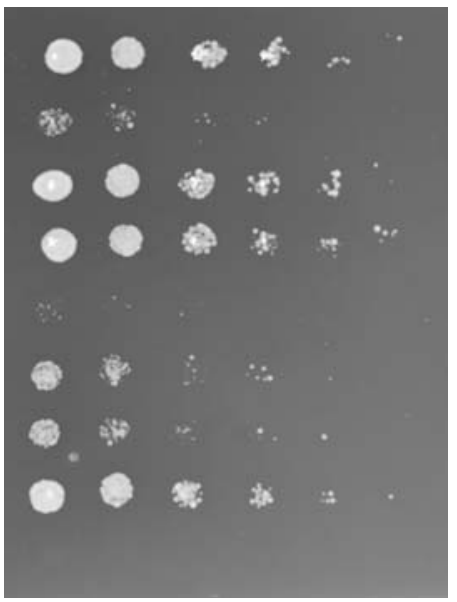

\begin{tabular}{|c|c|c|c|}
\hline 00 & 0 & $*$ & $\because \quad \because$ \\
\hline 0.0 & $\%$ & 4 & ix. \\
\hline 0 & 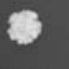 & * & ${ }^{x}$ \\
\hline 0 & 0 & $*$ & $x$ \\
\hline 0 & * & in: & ; \\
\hline 0 & 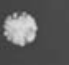 & * & $*$ \\
\hline 0 & 0 & $\approx$ & $z$ \\
\hline 0 & 0 & $\Leftrightarrow$ & \\
\hline 0 & $\dot{*}$ & & \\
\hline
\end{tabular}

$\mathrm{HA}$

Pgk1
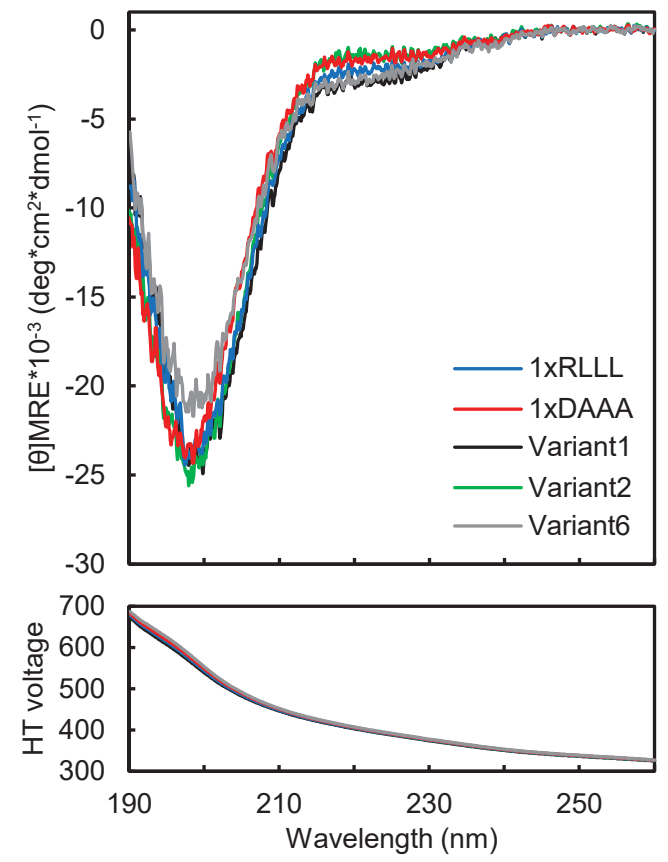
bioRxiv preprint doi: https://doi.org/10.1101/2021.12.22.473789; this version posted December $22,2021$. The copyright holder for this preprint (which was not certified by peer review) is the author/funder, who has granted bioRxiv a license to display the preprint in perpetuity. It is made available under aCC-BY-NC-ND 4.0 International license.

\section{Figure S4}

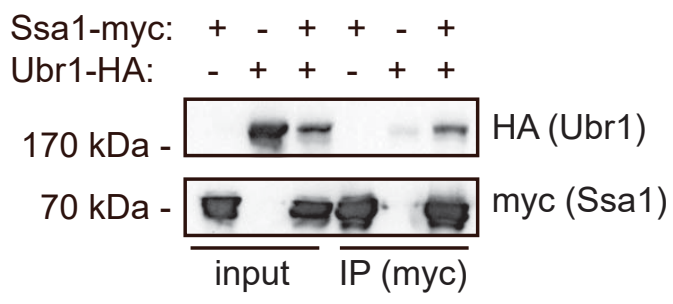

